\title{
Experimental and numerical study of steam gasification of a single charcoal particle
}

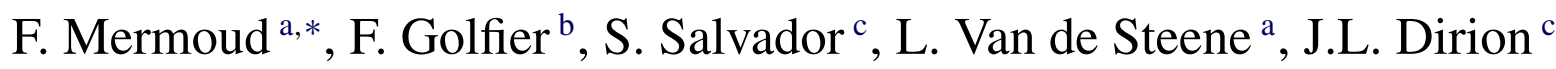 \\ ${ }^{a}$ CIRAD-Forêt, UPR 42 Biomasse Energie, TA 10/16, 73 Rue JF Breton, 34398 Montpellier Cedex 5, France \\ b LAEGO-ENSG-INPL, Rue du Doyen Marcel Roubault, BP 40, 54501 Vandoeuvre-les-Nancy, France \\ c LGPSD, UMR 2392 CNRS, Ecole des Mines d'Albi-Carmaux, Route de Teillet, 81013 Albi CT Cedex 09, France
}

\begin{abstract}
The present work deals with a study coupling experiments and modeling of charcoal gasification by steam at large particle scale. A reliable set of experiments was first established using a specially developed "macro-TG" apparatus where a particle was suspended and continuously weighed during its gasification. The main control parameters of a fixed-bed process were modified separately: steam gasification of beech charcoal spheres of different diameters $\left(10\right.$ to $30 \mathrm{~mm}$ ) was studied at different temperatures $\left(830\right.$ to $\left.1030{ }^{\circ} \mathrm{C}\right)$, different steam partial pressures $\left(0.1\right.$ to $\left.0.4 \mathrm{~atm} \mathrm{H}_{2} \mathrm{O}\right)$, and different gas velocities around the particle $(0.09$ to $0.30 \mathrm{~m} / \mathrm{s})$. Simulations with the particle model were performed for each case. Confrontations with experimental data indicate that the model pre-dictions are both qualitatively and quantitatively satisfactory, with an accuracy of $7 \%$, until $60 \%$ of conversion, despite the fact that the phenomena of reactive surface evolution and particle fracturing are not well understood. Anisotropy and peripheral fragmentation make the end of the process difficult to simulate. Finally, an analysis of the thermochemical situation is proposed: it is demonstrated that the usual homogeneous or shrinking core par-ticle models are not satisfying and that only the assumption of thermal equilibrium between the particle and the surrounding gas is valid for a model at bed scale.
\end{abstract}

Keywords: Steam gasification; Biomass; Modeling

\section{Introduction}

Biomass has received increasing attention in the past decades as an interesting renewable energy source. Nowadays, the gasification process has emerged as a clean and efficient way of producing gas from biomass. The transformation can be operated in a fixed-bed gasifier, where the reactant gases

\footnotetext{
* Corresponding author. Fax: +33467616515.

E-mail address: mermoud@ cirad.fr (F. Mermoud).
}

$\left(\mathrm{H}_{2} \mathrm{O}, \mathrm{CO}_{2}\right)$ react with a bed of charcoal particles (solid residue after wood pyrolysis). The syngas obtained can be sent to an internal combustion engine or a fuel cell in order to produce electricity. In this work, we focus on the steam gasification reaction, which is less studied in the literature than the $\mathrm{CO}_{2}$ gasification reaction, although steam gasification is preponderant (because more rapid) in industrial applications. The steam gasification of carbon is commonly described as

$\mathrm{C}_{\mathrm{f}}+\mathrm{H}_{2} \mathrm{O} \rightleftarrows \mathrm{CO}+\mathrm{H}_{2}$, 


\section{Nomenclature}

$A_{i} \quad$ frequency factor

$C_{j} \quad$ mass fraction of the species $j$

$C_{\mathrm{P}} \quad$ specific heat

$D_{j} \quad$ molecular diffusion coefficient of the species $j$ in nitrogen

$\mathbf{D}_{j}^{*} \quad$ dispersion tensor of the species $j$

$E_{i} \quad$ activation energy

$h \quad$ heat transfer coefficient

$k_{i} \quad$ kinetic parameter

$\mathrm{ks}_{\text {int }}$ intrinsic reactivity

$K_{j \text {,eq }} \quad$ constant for the species $j$ at equilibrium

$\mathbf{K}$ effective permeability

$m \quad$ mass

$m_{\text {ash }} \quad$ mass of ash

$m_{\text {init }} \quad$ initial mass

$M \quad$ molar mass

$N \quad$ number of species

$\mathrm{Nu} \quad$ Nusselt number

$p_{j} \quad$ partial pressure of the species $j$

$P \quad$ pressure

Pr Prandtl number

$Q \quad$ thermal source or sink term due to chemical reactions

$Q_{\text {rad }} \quad$ exchange term due to radiative transfer

$r_{\mathrm{P}} \quad$ cylindrical pore radius

$R \quad$ gas constant

$R_{\text {char }} \quad$ reaction term

$\mathrm{Re} \quad$ Reynolds number

$R_{j} \quad$ mass source or sink term of the species $j$ due to chemical reactions

$\begin{array}{ll}R_{\mathrm{p}} & \text { particle radius } \\ S & \text { surface } \\ \mathrm{Sc} & \text { Schmidt number } \\ \mathrm{Sh} & \text { Sherwood number } \\ S_{\mathrm{r}} & \text { reactive surface } \\ t & \text { time } \\ T & \text { temperature } \\ V & \text { volume } \\ \mathbf{V} & \text { superficial velocity } \\ X & \text { conversion }\end{array}$

Greek symbols

$\begin{array}{ll}\alpha & \text { mass transfer coefficient } \\ \varepsilon & \text { porosity } \\ \varepsilon^{*} & \text { critical porosity } \\ \lambda^{*} & \text { effective conductivity } \\ \mu & \text { viscosity } \\ \rho & \text { density } \\ \tau & \text { tortuosity }\end{array}$

\section{Subscripts}

$\beta \quad$ fluid phase in the charcoal particle

$\eta \quad$ charcoal particle

$\sigma \quad$ solid phase in the charcoal particle

$\omega \quad$ surrounding gas phase

$\infty \quad$ away from the particle

\section{Superscripts}

0 at zero conversion

surf at the surface where $\mathrm{C}_{\mathrm{f}}$ represents a free active site on the carbon surface. This endothermic reaction occurs at temperatures in the range $800-1200^{\circ} \mathrm{C}$, and requires $\mathrm{H}_{2} \mathrm{O}$ and heat supply inside the bed.

Today, the design and operation of gasifiers require more knowledge of biomass reactivity, which is highly influenced by parameters such as temperature, steam partial pressure, and particle size. At this time, several studies have been carried out at a microscopic scale (using TG apparatus) [1-4], but only a few at a macroparticle scale [5-7].

The influence of operating conditions on the gasification kinetics of various wood chars and coals has been widely studied in the literature, with both $\mathrm{CO}_{2}$ and $\mathrm{H}_{2} \mathrm{O}$ as the oxidant. Gasification was found to be very sensitive to temperature [1-8]. The partial pressure of the oxidant $\left(\mathrm{CO}_{2}\right.$ or $\left.\mathrm{H}_{2} \mathrm{O}\right)$ also greatly influences gasification kinetics [1-5,9]. The effects of temperature and oxidant partial pressure are in accordance with the kinetics commonly used (LangmuirHinshelwood or Arrhenius); i.e., reactivity increases when the temperature or the oxidant partial pressure increases.

Several authors $[5,8,9]$ studied the influence of the size of a particle on its gasification. The particle size was found to have no effect by certain authors [9] and a retarding effect when the particle size increases by other authors $[5,8]$. However, the comparison of the different results is interesting as far as similar operating conditions (in terms of size range, temperature, oxidant partial pressure, particle alone or char bed) are considered, in order to remain within the same reaction regime.

Pyrolysis conditions (heating rate, final temperature, residence time, and pressure) are known to affect the reactivity of the charcoal obtained. Many authors [6,10-14] studied the effect of pyrolysis conditions on the reactivity of the charcoal obtained. These parameters will not be treated here, but we investigated the influence of pyrolysis heating rate in another paper [15]. 
Before continuing with the state of the art of modeling, a few comments are necessary. From a physical point of view, gasification, drying, combustion, and pyrolysis phenomena can be seen as different processes of the same type: the thermal conversion of a porous particle. They are characterized by some common features such as species transport in the pore space coupled to heat transfer in the solid phase, heterogeneous reaction between one or more species and the solid matrix, and drastic evolution of the microstructure. A similar approach can be used to model these different phenomena and, consequently, we will not distinguish between these models in the following discussion. Given the large number of models developed, we do not pretend here to present an exhaustive review, but just to give the reader an overview of the different numerical approaches.

Thermal conversion is usually assumed to be uniform at the surface of the particle in order to consider one-dimensional modeling. If some of the models use simplified approaches, such as a reacting-core model—which presumes a uniform reaction in the entire particle—or a shrinking-core model—which presumes reactions on the outer surface [16-18]-the earlier works are based on the global solving of the mass and energy conservation equations. Kung [19], for example, has developed a model of heat and mass transfers during pyrolysis. Lee et al. [20] have modeled the transient behavior of carbon particle ignition and oxidation.

Regarding the gasification process more specifically, three or four single-particle models can be exhibited. The simplest one, developed by Gobel et al. [17], is based on a shrinking-core model and Langmuir-Hinshelwood kinetics for the reaction term. Dasappa et al. [7] have modeled the gasification of an isolated single charcoal sphere initially in a carbon dioxide-nitrogen mixture only. This model was later extended to the steam-char reaction [21]. It describes the diffusion-convection and reaction processes of the species and energy in the pores by conservation equations. Immediate outflow of the gas phases is assumed to represent convective transport. Improved Langmuir-Hinshelwood kinetics is used for the gasification reaction term. If the numerical results fit well the experimental results for the $\mathrm{CO}_{2}$-char reaction up to $60 \%$ of conversion, the comparison is less accurate for steam gasification.

A similar approach has been adopted by Peters and Bruch [22]. Their model, which describes the overall thermal conversion of solid fuel particles, takes into account steam gasification. It is based on solving unsteady spherically symmetric one-dimensional conservation equations. $N$ th order kinetics is used to treat the heterogeneous reaction term in order to represent a wide range of applications (pyrolysis, com- bustion, and gasification). The convective transport is, however, strongly simplified and no rigorous validation of the model from experimental gasification results is presented.

This review of existing models of thermal conversion emphasizes the need for a model able to capture all the physics at particle scale. This objective can only be reached thanks to a modeling approach validated by a fine experimental study under precisely controlled operating conditions. In particular, a complete investigation of the effects of all operating conditions in the model (temperature, particle size, or $\mathrm{H}_{2} \mathrm{O}$ partial pressure), validated by the experiments, must be performed. As a consequence, the approach adopted here, coupling model and experiments, is essential.

This paper first presents the experimental part of our work. The macro-TG reactor and the results obtained with this experimental apparatus are described. A detailed observation of the charcoals during gasification is also performed (macroscopic pictures, SEM pictures, X-ray tomography). The second part of this work deals with the development of the particle model. The governing equations for the conservation of mass, species, and energy are developed and the underlying assumptions at the basis of this development are justified. Then the numerical implementation of our model is presented. The numerical schemes used to solve the set of equations and boundary and initial conditions are detailed, as well as the expression of the effective coefficients. Particular attention is paid to the choice of reaction kinetics. Last, the performed simulations are compared to the experimental gasification results obtained for a single charcoal particle suspended inside a controlled environment. Based on these results, different questions such as the occurrence of local thermal equilibrium or local mass equilibrium, but also the characterization of the limiting mechanisms (heat transfer, mass transfer, or reaction kinetics) of the gasification process, are discussed. To select the best assumptions on the modeling of a fixed bed, the impact of simplifying assumptions (shrinking-core and reacting-core model, absence of limitation by external heat and mass transfers) are also considered and analyzed.

\section{Experimental study}

\subsection{Description of the experiments}

\subsubsection{Experimental setup}

The general principle of our macro-TG reactor consists in holding a charcoal particle inside a reactor at atmospheric pressure, swept by the oxidizing agent $\mathrm{H}_{2} \mathrm{O}$ in $\mathrm{N}_{2}$ gas and at a controlled temperature. 


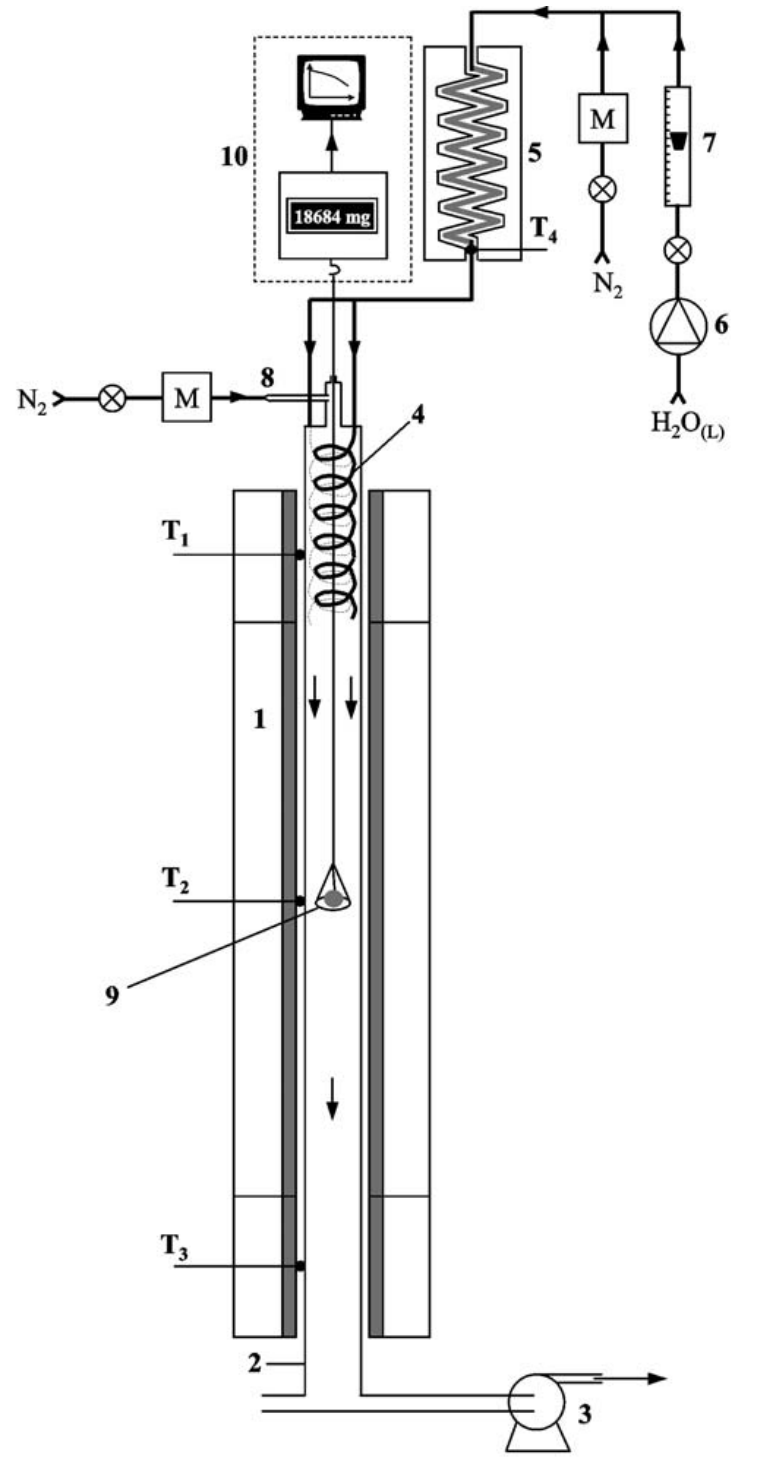

(1) Electrical furnace (2) Quartz tube (3) Extractor (4) Preheater (5) Evaporator (electrically heated) (6) Peristaltic pump (7) Variable area flowmeter (8) Leak flow compensator (9) Hanging mechanism (10) Weighing/Recording device $\left(T_{i}\right)$ Regulation thermocouple (M) Mass flowmeter/controller

Fig. 1. Macro-TG experimental apparatus.

The weight of the particle is continuously monitored in order to follow the conversion of the charcoal. The experimental setup is presented in Fig. 1. The reactor is a 2-m-long quartz reactor heated electrically (1). The atmosphere is generated by a $\mathrm{N}_{2}$ flow controlled by a mass flowmeter/controller (M) and a liquid-water flow controlled by a rotameter (7) and directed to a steam generator (5), whose output temperature is fixed at $200^{\circ} \mathrm{C}$. The gas mixture is then fed to two coiled tubes (4) inside the reactor to preheat the atmosphere gas. The precision load cell (10) holds a nickel hanging wire and basket (9) in which particles are placed.

One difficulty encountered when constructing the macro-TG was to control the gas flow through the holding wire aperture at the top of the reactor. Indeed,
Table 1

Analysis of the initial beechwood samples

\begin{tabular}{lr}
\hline Proximate analysis & $(\mathrm{wt} \%)$ \\
Ash & 0.38 \\
Volatile matter & 82.45 \\
Fixed carbon (by difference) & 17.17 \\
Ultimate analysis & $(\mathrm{wt} \%)$ \\
C & 44.16 \\
H & 5.48 \\
O (by difference) & 50.36 \\
\hline
\end{tabular}

steam should not escape from the reactor, to ensure the molar fraction of $\mathrm{H}_{2} \mathrm{O}$ in the reactor atmosphere gas and to prevent water condensation. Neither should air enter the reactor, to avoid a reaction between carbon and oxygen. A $4 \mathrm{NL} \min ^{-1}$ flow of $\mathrm{N}_{2}$ was then fed through a small tube (8) to the vertical tube surrounding the hanging wire in order to create a counterflow. The flow rate of this additional $\mathrm{N}_{2}$ actually entering the reactor was measured accurately by the tracer gas method and taken into account in the composition of the atmosphere gas.

At a given degree of conversion, the charcoal particle can be quenched and recovered for observation and morphological analysis. For this purpose, the gasifying particle is submitted to an inert $\left(\mathrm{N}_{2}\right)$ atmosphere while it is removed from the reactor, to avoid its combustion during its cooling outside the reactor.

\subsubsection{Sample preparation}

The initial samples consisted of beechwood spheres. The proximate and ultimate analysis of the wood, measured in compliance with standards NFM03-003 and NF-B55-101, are presented in Table 1. The volatile matter percentage is as high as $82 \%$, and the ash content of the wood is low: $0.38 \%$.

The wood spheres, initially 10,20 , or $30 \mathrm{~mm}$ in diameter, were first pyrolyzed under $\mathrm{N}_{2}$ before being gasified with $\mathrm{H}_{2} \mathrm{O}$. The wood particles were placed in a refractory steel box swept with nitrogen. The temperature was increased slowly_at a heating rate of $2.6 \mathrm{~K} \mathrm{~min}^{-1}$-from room temperature to $800^{\circ} \mathrm{C}$. The furnace was kept $1 \mathrm{~h}$ at this temperature and then stopped before the sample was cooled with nitrogen.

Size and mass of the charcoal particles obtained after pyrolysis at a heating rate of $2.6 \mathrm{~K} \mathrm{~min}^{-1}$ were precisely measured; their apparent density and porosity were then calculated (cf. Table 2). We observed that the original wood spheres became ovoid after pyrolysis: the difference between the lesser and the greater dimension was as high as $30 \%$. This anisotropic shrinkage results from the nonisotropic properties of the initial wood. Indeed, the initial wood presents a fibrous structure with many more longitu- 
Table 2

Properties of the samples before and after pyrolysis

\begin{tabular}{|c|c|c|c|c|}
\hline & & \multicolumn{3}{|c|}{ Average initial size } \\
\hline & & $10 \mathrm{~mm}$ & $20 \mathrm{~mm}$ & $30 \mathrm{~mm}$ \\
\hline \multicolumn{5}{|l|}{ Initial beechwood: } \\
\hline measured diameter of a particle & $\mathrm{mm}$ & 10.2 & 20.09 & 29.89 \\
\hline weight of a particle (dry basis) & $\mathrm{g}$ & 0.372 & 2.869 & 9.314 \\
\hline apparent density (dry basis) & $\mathrm{kg} \mathrm{m}^{-3}$ & 664 & 676 & 666 \\
\hline \multicolumn{5}{|l|}{ Charcoals: } \\
\hline equivalent diameter of a particle & $\mathrm{mm}$ & 7.05 & 14.07 & 20.87 \\
\hline weight of a particle & $\mathrm{g}$ & 0.093 & 0.742 & 2.323 \\
\hline apparent density & $\mathrm{kg} \mathrm{m}^{-3}$ & 507 & 509 & 488 \\
\hline porosity & $\%$ & 73 & 73 & 74 \\
\hline
\end{tabular}

dinal cells than ray cells. The alignment of cellulose microfibrils in the longitudinal cell walls gives the wood fibers high stiffness. Byrne and Nagle [23] measured the reduction of dimensions of different woods during pyrolysis, and observed a shrinkage 10 to $20 \%$ less in the longitudinal direction than in the perpendicular ones, resulting from this longitudinal stiffness.

The equivalent sphere diameter was calculated as the average of the three different dimensions (cf. Table 2). It can be noted that the charcoal particle volume is approximately three times smaller than that of the initial wood particles. Nevertheless, no cracks could be observed at the surface of the charcoal particles.

No marked differences in apparent charcoal densities $\rho_{\eta}$ were observed: values range from 488 to $509 \mathrm{~kg} \mathrm{~m}^{-3}$ for the three different particle sizes. It can be inferred that there are no significant differences in the properties of the charcoals from 10-, 20-, or 30mm wood spheres.

The present results can also be expressed in terms of particle porosity. The density of the solid phase $\rho_{\sigma \eta}$ —carbon and ash — was measured using helium pycnometry for the three particle sizes at a similar value of $1900 \mathrm{~kg} \mathrm{~m}^{-3}$. This enables calculation of the porosity $\varepsilon_{\eta}$ of the particles as indicated in Table 2 :

$\varepsilon_{\eta}=1-\frac{\rho_{\eta}}{\rho_{\sigma \eta}}$.

Resulting from the similarity of the apparent densities, the porosity is equivalent for the three charcoals and close to $73 \%$.

In the following, in order to simplify the notation, particles will be referenced by their initial size before pyrolysis, 10,20 , or $30 \mathrm{~mm}$.

\subsubsection{Experimental procedure}

Experiments were conducted at atmospheric pressure under different operating conditions:

- temperature: 830,930 , or $1030^{\circ} \mathrm{C}$;
- $\mathrm{H}_{2} \mathrm{O}$ partial pressure: $0.1,0.2$, or 0.4 atm;

- gas velocity: $0.09,0.14$, or $0.30 \mathrm{~m} \mathrm{~s}^{-1}$;

- initial particle size: 10,20 , or $30 \mathrm{~mm}$.

Reference conditions for experiments were 10-mmdiameter particles, temperature $930^{\circ} \mathrm{C}$, steam partial pressure $0.2 \mathrm{~atm}$, and gas velocity $0.14 \mathrm{~m} \mathrm{~s}^{-1}$. From this reference, each parameter was varied individually in the specified ranges.

The operating conditions in terms of temperature, steam partial pressure, and gas velocity around the particle were well controlled, which constitutes an essential condition for carrying out a very detailed parametric study.

The reactor was first heated under $\mathrm{N}_{2}$ at the operating temperature -830 to $1030^{\circ} \mathrm{C}$ - until a stable regime was achieved. The basket was then lifted from the bottom of the reactor and hung on the load cell. A constant mass achieved under $\mathrm{N}_{2}$ ensured that adsorbed gas at the surface of the charcoal $\left(\mathrm{H}_{2} \mathrm{O}\right.$, hydrocarbons) was released before the gasification with $\mathrm{H}_{2} \mathrm{O}$. The water flow was then established, producing the desired atmosphere-10 to $40 \%$ mole fraction of $\mathrm{H}_{2} \mathrm{O}$ in $\mathrm{N}_{2}$. The mass of the sample progressively decreased until a constant mass - that of ash-was achieved to conclude a test.

Experiments with 20- or 30-mm-diameter spheres (14.07 and $20.87 \mathrm{~mm}$ after pyrolysis) were carried out with a single particle to avoid interactions. Experiments with $10-\mathrm{mm}$-diameter spheres $(7.05 \mathrm{~mm}$ after pyrolysis) were made with seven particles together, because the weight of a single charcoal particle was very small ( $<100 \mathrm{mg})$; using several particles increased the signal/noise ratio of the load cell by increasing the total mass of the sample. The particles were arranged in a horizontal plane and were not in contact. Indeed, contact between the particles could lead to slowing down of the external heat and mass transfers, resulting in steam impoverishment and temperature decrease around the particle. 


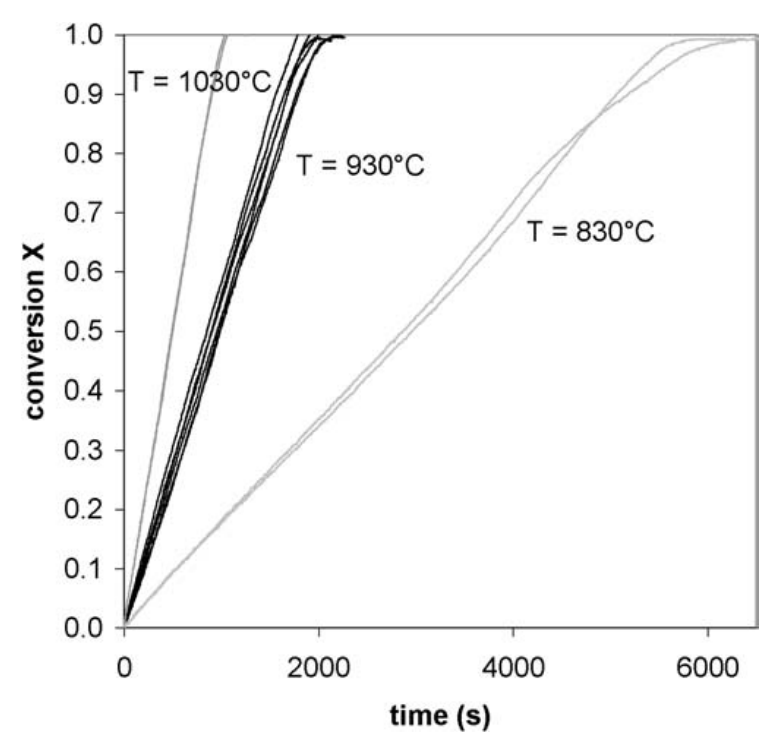

Fig. 2. Gasification of charcoal particles at different temperatures: 830,930 , and $1030^{\circ} \mathrm{C}$ (initial diameter $10 \mathrm{~mm}$, $\left.P_{\mathrm{H}_{2} \mathrm{O}}=0.2 \mathrm{~atm}\right)$.

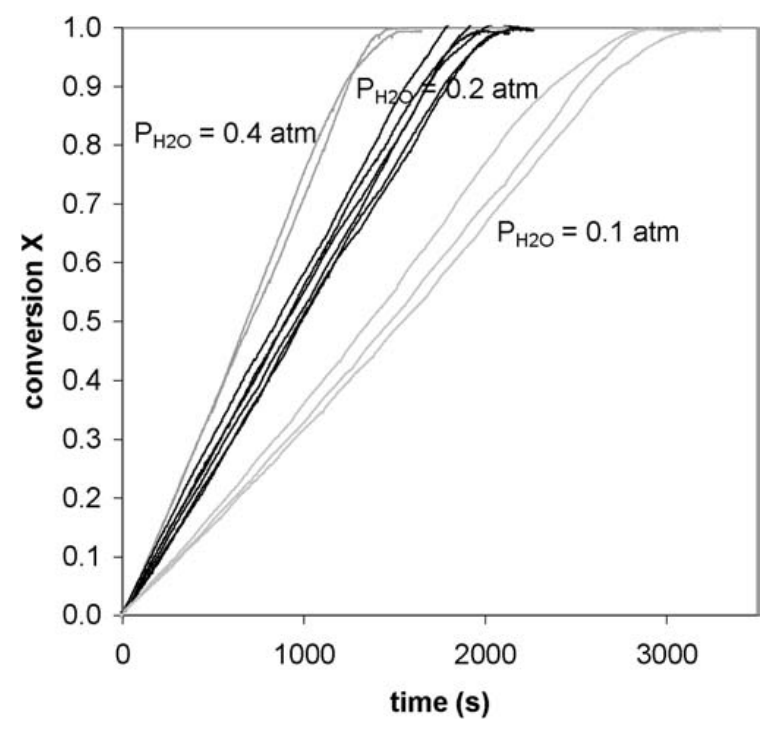

Fig. 3. Gasification of charcoal particles under different steam partial pressures: $0.1,0.2$, and $0.4 \mathrm{~atm}$ (initial diameter $10 \mathrm{~mm}, T=930^{\circ} \mathrm{C}$ ).

\subsection{Observation of the results}

\subsubsection{Curves observation}

The conversion $X$ during steam gasification was calculated following the equation

$$
X=\frac{m_{\text {init }}-m}{m_{\text {init }}-m_{\text {ash }}} .
$$

Conversion was plotted versus time (cf. Figs. 2-4). All the experiments were carried out several times to check repeatability. A deviation of about $10 \%$ for six tests under our conditions was observed. The repeatability achieved is acceptable considering the wood heterogeneity and the large size of the particles. Some

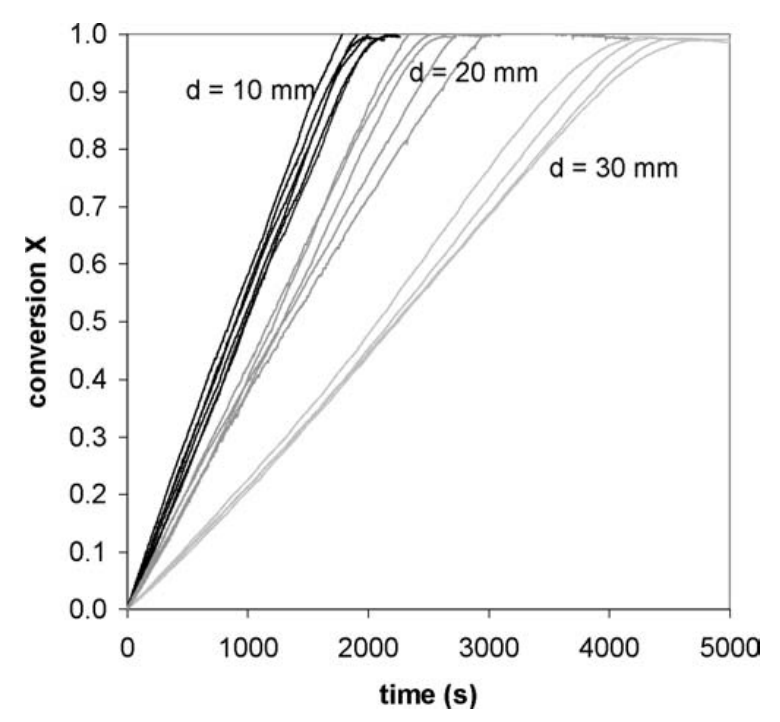

Fig. 4. Gasification of charcoal particles of different initial diameters: 10,20 , and $30 \mathrm{~mm}\left(T=930^{\circ} \mathrm{C}, P_{\mathrm{H}_{2} \mathrm{O}}=\right.$ $0.2 \mathrm{~atm})$.

dispersion still exists, showing that repeating all experiments was necessary.

The examination of the results first indicates a quasi-constant $\mathrm{d} X / \mathrm{d} t$ during nearly $90 \%$ of gasification. Similar results have already been observed by other authors, but during gasification by $\mathrm{CO}_{2}[5-7$, 10]. It has to be noticed that this straight shape is characteristic of biomass chars, whereas coal chars exhibit a classical rounded shape, with a decrease in gasification rate at the end, which can be explained by a decrease in the surface area available for the reaction at the end [24-26]. Indeed, in the case of biomass charcoal, reactivity continuously increases during the conversion, due to continuous increase in the surface area $[7,27]$, whereas in the case of coal char, the surface area first increases at the beginning of the conversion and then decreases after reaching a peak at a certain degree of conversion (typically before $50 \%$ conversion), as observed by previous authors in the case of $\mathrm{CO}_{2}$ gasification [24-26].

Dutta et al. [24] argue that the random structure of coal chars, with large holes and numerous microcapillarities, observed on their SEM photographs, makes some pores inaccessible to reactant gas at the beginning of the conversion. The reaction opens up the pore volume by enlarging or creating the connections between the pores: the surface area available for reaction is then increased up to a point at which the rate of formation of a new area is lower than the rate of destruction of the old area by collapse of the solid linkage between the adjoining pores [24,26]. Based on their SEM photographs, Dasappa et al. [7] explain the linear increase of the surface area by the high ordering of the pores in the biomass char, mainly consisting of a regular network of longitudinal tubes. Therefore the 

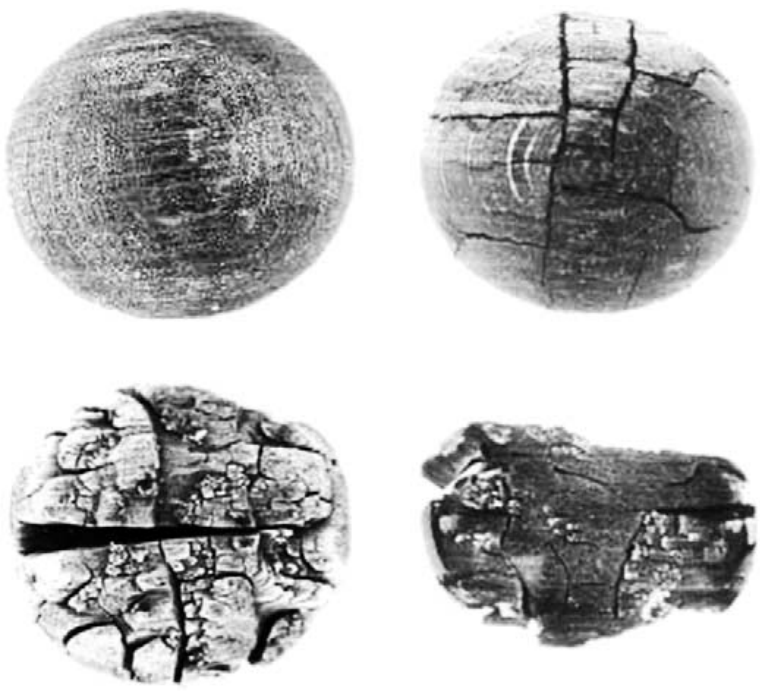

Fig. 5. Macroscopic evolution of a gasifying particle $(0 \%$, $20 \%, 50 \%, 70 \%$ conversion).

cell walls are consumed regularly until very high levels of conversion without any coalescence.

If the curves are observed carefully, it can be seen that gasification slightly accelerates after $50 \%$ conversion. This could be due to fracturing of the particle, which would help the diffusion of the reactant inside the particle, facilitating the reaction. This assumption is supported by our experiments (cf. Fig. 5), in which fracturing clearly appears after only $20 \%$ conversion on $30 \mathrm{~mm}$ diameter particles. Moreover, the curves almost merge at the beginning of the conversion (when the particle is not yet fractured) and curve dispersion increases after 50\% conversion (when fracturing is high): this can be seen in Fig. 4 for the gasification of 20- and 30-mm-diameter particles. Fracturing could be responsible for this curve dispersion, since this phenomenon is not repeatable. However, fracturing does not appear to have marked effects on particle gasification, since curve dispersion is lower than $10 \%$.

It can be noticed in Fig. 4 that dispersion is greater on large particles than on small particles. There are two explanations for this deviation: (i) the fracturing is amplified on large particles; (ii) the experiments with 10-mm particles are carried out with seven particles together and thus lead to averaged results, whereas the experiments with 20 - or 30-mm particles are made with a single particle.

\subsubsection{Influence of parameters}

Gasification is very sensitive to temperature, as shown by experiments at 830,930 , and $1030^{\circ} \mathrm{C}$ (cf. Fig. 2). It can be seen that the reaction is very slow at $830^{\circ} \mathrm{C}$. A difference in $\mathrm{d} X / \mathrm{d} t$ as high as 6.5 to 1 is observed between experiments at 1030 and $830^{\circ} \mathrm{C}$. These results confirm that temperature is the most influencing parameter on gasification kinetics, as ob- served by other authors with $\mathrm{H}_{2} \mathrm{O}[1-3,21]$ or $\mathrm{CO}_{2}$ [5-7].

Experiments carried out with mixtures of $\mathrm{H}_{2} \mathrm{O} / \mathrm{N}_{2}$ at $10 \%, 20 \%$, and $40 \%$ mol of steam (cf. Fig. 3) confirmed that oxidant partial pressure influences gasification, as observed by other authors [1-3,21]. The $\mathrm{d} X / \mathrm{d} t$ are in a ratio of 1.9 for $\mathrm{H}_{2} \mathrm{O}$ partial pressure varying from 0.4 to $0.1 \mathrm{~atm}$.

The influence of gas velocity around the particle has been investigated by several authors [5,7]. Standish and Tanjung [5] varied the gas velocity around a 22-mm particle between 0.0087 and $0.0433 \mathrm{~m} \mathrm{~s}^{-1}$. They observed that the time for complete conversion increased until a peak at $0.026 \mathrm{~m} \mathrm{~s}^{-1}$ and then decreased before reaching a constant value after $0.0433 \mathrm{~m} \mathrm{~s}^{-1}$. Dasappa et al. [7] carried out the same kind of experiments on 10-mm-diameter particles. They also observed a peak, but at a lower gas velocity (referred to the same Re). No tangible explanation was given for this phenomenon. A competition between downward thermal convection of the colder gas at the surface of the particle, downward forced convection of the atmosphere gas flux and upward mass convection of the light $\mathrm{H}_{2}$ species can be an explanation. In the present study, the effect of gas velocity on gasification rate was investigated thanks to experiments at higher velocities of $0.09,0.14$, and $0.30 \mathrm{~m} \mathrm{~s}^{-1}$; the diameter of the particles was $10 \mathrm{~mm}$. A discrepancy is observed in but all these curves can be included in the error interval of experiments. Based only on these experiments, it was impossible to distinguish the uncertainty due to the repeatability of the experiments and the real effect of the gas velocity. This study, however, suggests that gas velocity had a gentle influence on gasification.

The gasification rate decreases when the particle size increases, as illustrated by experiments with charcoals from wood spheres of 10,20 , and $30 \mathrm{~mm}$ initial diameter (cf. Fig. 4). This observation shows that internal transfers are influencing the reaction under our operating conditions, i.e., with macroscopic particles.

\subsubsection{Charcoal observation}

To understand the internal structure evolution, gasifying charcoals were analyzed in different ways, from macroscopic to very detailed observation, using techniques such as adsorption/desorption analysis, SEM, or X-ray tomography.

Macroscopic observation It is interesting to study the evolution of a gasifying particle. For this purpose, a charcoal particle with an initial diameter of $30 \mathrm{~mm}$ was partially gasified at 20,50 , and $70 \%$ under $930^{\circ} \mathrm{C}$ and $0.2 \mathrm{~atm} \mathrm{H}_{2} \mathrm{O}$ and recovered for macro and microscopic observations. The size of the particle was measured at each degree of conversion (cf. 


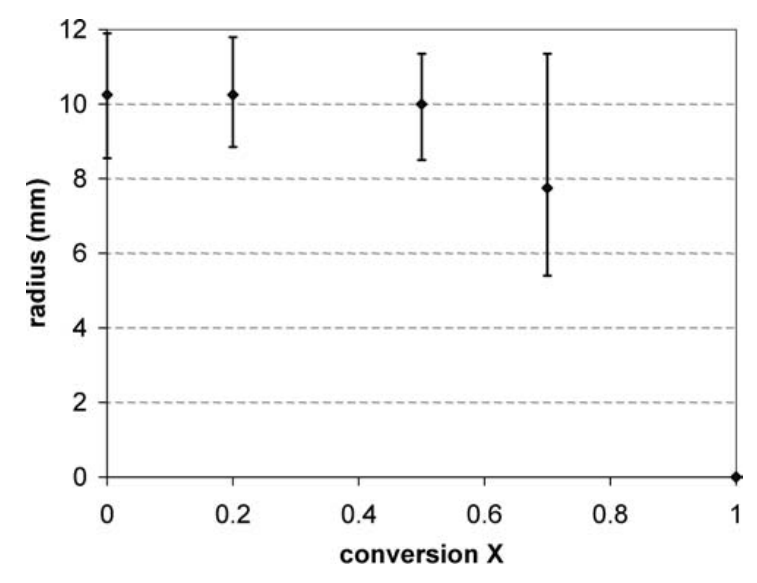

Fig. 6. Radius evolution throughout gasification of a 30-mm initial diameter particle $\left(T=930^{\circ} \mathrm{C}, P_{\mathrm{H}_{2} \mathrm{O}}=0.2 \mathrm{~atm}\right)$.

Fig. 6). The average values of the three dimensions of the charcoal are surrounded by an error interval representing the ovoid shape of the particle. Fig. 6 shows that the size of the particle is almost constant until $50 \%$ conversion but decreases by $25 \%$ when $70 \%$ conversion is reached. Dasappa et al. [7] observed in their experiments that the size of the charcoal particle did not change until $60 \%$ conversion. This observation makes it possible to conclude that the conversion is not only superficial but takes also place inside the charcoal, and disproves simplified approaches such as shrinking-core models. It can be noticed in Fig. 6 that the maximal dimension is almost constant even at $70 \%$ conversion, whereas the minimal radius decreases strongly, attesting the anisotropic behavior of the charcoal during its gasification.

We can see in Fig. 5 that fracturing appears after only $20 \%$ conversion. At $50 \%$ conversion, the cracks are very deep but the particle retains its initial size. At $70 \%$ conversion, the particle loses its initial shape and size. The pictures show that no large ash layer forms at the surface of the charcoal particle, implying that the ash is removed during gasification.

Adsorption/desorption analysis To determine the pore size distribution and the total surface area of the charcoals, $\mathrm{N}_{2}$ and Ar adsorption/desorption analysis was performed. The $10-\mathrm{mm}$ charcoals presented a large surface area of $617 \mathrm{~m}^{2} \mathrm{~g}^{-1}$, consisting mainly in micropores $(<2 \mathrm{~nm})$, with a microporous surface area of $578 \mathrm{~m}^{2} \mathrm{~g}^{-1}$. This value is higher than other values reported in the literature, generally lower than $500 \mathrm{~m}^{2} \mathrm{~g}^{-1}$ [28]. It can be noticed that the surface area of biomass chars is usually higher than that of coal chars, which is typically lower than $200 \mathrm{~m}^{2} \mathrm{~g}^{-1}$ $[24,25]$.

Scanning electron microscopy (SEM) SEM observations have been performed on our charcoals, but only qualitative analysis could be performed on the

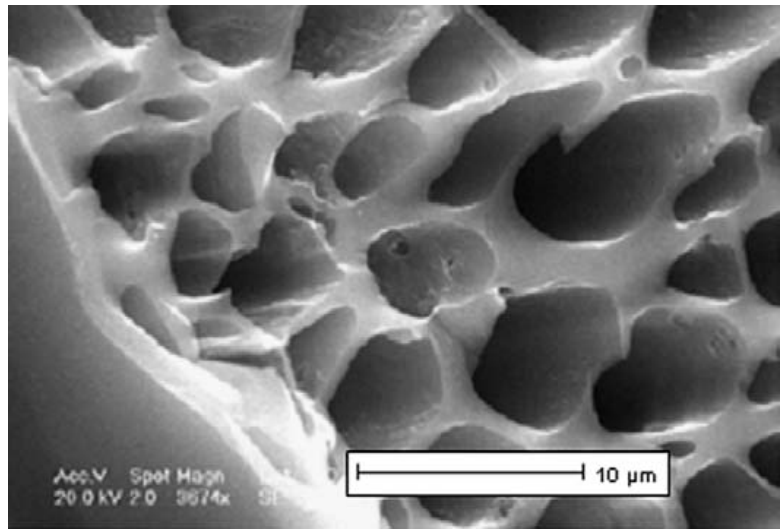

Fig. 7. SEM picture of initial charcoal, transversal section.

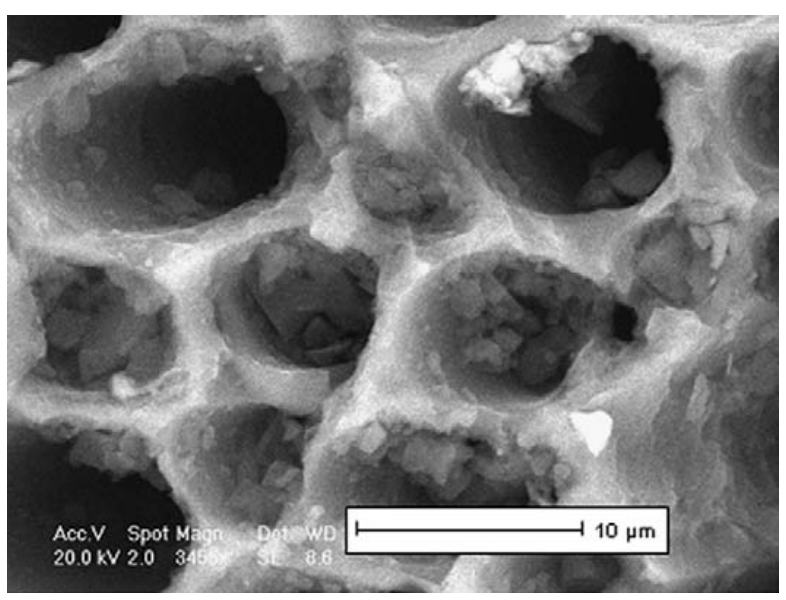

Fig. 8. SEM picture of $70 \%$ converted charcoal, transversal section.

photographs. Nevertheless, the fibrous structure of the nonconverted charcoal, corresponding to the initial wood structure, could easily be observed. The structure of well-organized, longitudinal tubes observed by several authors [5,7] is confirmed by our photographs. This structure is very different from the coal char structure observed by Dutta et al. [24], which has no fibers and is very heterogeneous.

Only macroporosity could be observed using SEM. Microporosity is very difficult to detect with this technique, even if BET measurements revealed a very large micropore surface area. The actual reactive surface of our charcoals, i.e., at nanometer scale, could not be observed.

The same charcoal particle was observed after $70 \%$ conversion in order to compare the difference in structure of the two charcoals. At high magnification, Figs. 7 and 8 exhibit a marked difference in roughness between the two charcoals: the carbon matrix seems to be damaged by the reaction, corroborating an increase of the surface area during conversion.

Similarly, Manocha et al. [27] observed in their experiments a thinning of the pore walls during conversion and the creation of pores within the walls, increasing the surface area available for reaction. This 


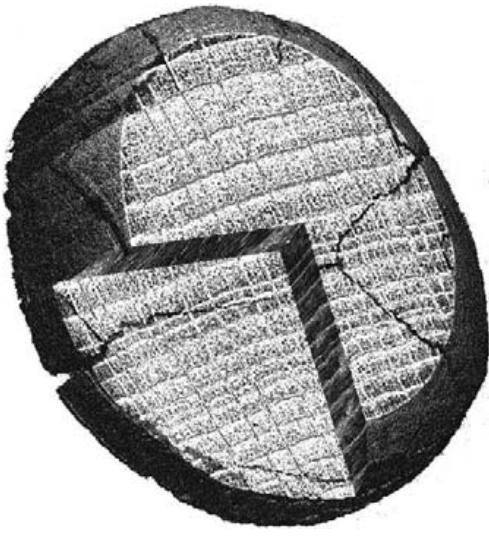

Fig. 9. 3D view of $20 \%$ converted charcoal (obtained by $\mathrm{X}$-ray tomography).

observation attests a parallel evolution of the microand the macroporosity.

$X$-ray tomography A 30-mm charcoal sphere gasified until $20 \%$ conversion was analyzed by X-ray tomography. The tomography apparatus is a Skyscan 1092-3 with a spatial resolution of $5 \mu \mathrm{m}$. The wood char was scanned every $37.71 \mu \mathrm{m}$ along the longitudinal direction and 413 slices were obtained. From all the sections, a 3D reconstruction was performed using Noesys Software. This detailed analysis of the internal structure of the charcoal confirms the extent of the fracturing phenomenon during the gasification process. Indeed, unlike what could be expected from superficial observation of the charcoal surface, some cracks penetrate to the heart of the particle even at a low degree of conversion $(X=0.2)$, as illustrated in Fig. 9.

To further analyze these first observations, an image processing method was applied to cross-section views. The contrast of density was accentuated in order to observe the degree of conversion of the charcoal. A characteristic view is represented in Fig. 10. The brighter the picture, the greater the porosity. Apart from a small area close to the external surface, where gasification probably took place, the porosity seems to be greater in the center of the particlethat is, connected to the surface of the particle by a fracture-than on its surface. Even if this analysis is more qualitative than quantitative, it suggests a greater gasification process close to the heart, resulting from the increase of diffusion transfer along the fracture.

\subsection{Conclusion}

Experiments were carried out on a macro-TG reactor in which charcoal particles of different sizes were gasified at different temperatures, $\mathrm{H}_{2} \mathrm{O}$ partial pressures, and gas velocities. The results obtained show a

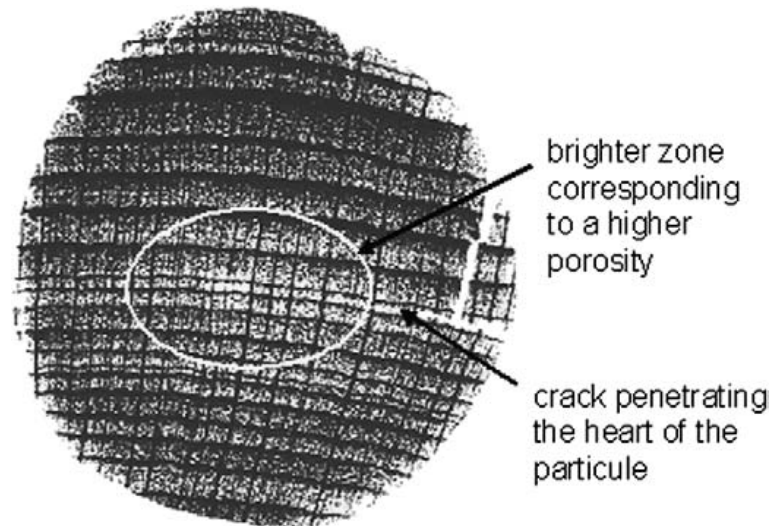

Fig. 10. Cross-section view of $20 \%$ converted charcoal (obtained by X-ray tomography).

marked effect of temperature, $\mathrm{H}_{2} \mathrm{O}$ partial pressure, and size on the gasification process. Gas velocity, however, does not seem to have any effect in the case studied.

Charcoals were observed at different degrees of conversion, using macrophotography, SEM, and Xray tomography. These different techniques enabled us to observe the evolution of size and porosity of the particle and to reveal the occurrence of fracturing during gasification.

Based on these results, the development of a numerical model able to capture all the physics at particle scale seems to be necessary in order to have a better understanding of the transfer mechanisms involved. This will be the focus of the following section.

\section{Description of the model}

\subsection{Mathematical formulation}

The model presented in the following was developed to predict the gasification process of a spherical particle of wood char (excluding its pyrolysis step). The charcoal particle, identified by the subscript $\eta$, can be seen as a porous medium including a fluid and a solid region consisting mainly of carbon, identified as the $\beta$-phase and the $\sigma$-phase, respectively. The simplifying assumptions employed here include the following:

- Macroscopic properties (pressure, concentration, temperature) are assumed to be uniform at the charcoal surface and the particle is considered to remain spherical throughout gasification;

- Diffusive transport is assumed to be governed by the Fick law;

- Tar formation is not taken into account;

- Dufour and Soret effects are not considered. 
Under these assumptions, the overall mass, species, and energy conservation equations can be simplified into the spherically symmetric, one-dimensional form. All the equations of the model are gathered into Appendix A. The governing equations for the conservation of mass, species, and energy are as follows:

$$
\begin{aligned}
& \nabla P_{\eta}=-\mu \mathbf{K}_{\eta}^{-1} \cdot \mathbf{V}_{\eta}, \\
& \frac{\partial\left(\varepsilon_{\eta} \rho_{\beta \eta}\right)}{\partial t}+\nabla \cdot\left(\rho_{\beta \eta} \mathbf{V}_{\eta}\right)=\sum_{j=1}^{n} R_{j \eta}, \\
& \frac{\partial \varepsilon_{\eta}}{\partial t}=\frac{1}{\rho_{\sigma \eta}} \sum_{j=1}^{n} R_{j \eta}, \\
& \underbrace{\partial\left(\varepsilon_{\eta} \rho_{\beta \eta} C_{j \eta}\right)}_{\text {accumulation }}+\underbrace{\nabla t \cdot\left(\rho_{\beta \eta} \mathbf{V}_{\eta} C_{j \eta}\right)}_{\text {convection }} \\
& =\underbrace{\nabla \cdot\left(\rho_{\beta \eta} \mathbf{D}_{j \eta}^{*} \cdot \nabla C_{j \eta}\right)}_{\text {diffusion }}+\underbrace{R_{j \eta}}_{\text {reaction }},
\end{aligned}
$$

$P_{\eta}=\frac{\rho_{\beta \eta} R T_{\eta}}{M_{\beta \eta}}$.

The homogeneous gas phase reactions inside the charcoal particle are not taken into account. As for the equation of state, the ideal gas law was applied. No simplifying assumption is adopted concerning the evolution of the charcoal particle during the gasification, Eq. (6). Thus, a description of the transport of products in conjunction with the evolution of porosity covers the entire range from the limiting case of a reacting core (reaction-rate limited regime) to the shrinking-core model (mass-transfer limited).

Whereas the overall gasification process implies up to seven different chemical species involved in the various chemical reactions (water-gas shift reaction, hydrogenation, etc.), we limit our model in the first step to the major reaction, given by Eq. (1). In the context of single-particle gasification, others reactions are negligible. Thus, we have four species involved: $\mathrm{H}_{2} \mathrm{O}$, $\mathrm{CO}, \mathrm{H}_{2}$, and $\mathrm{N}_{2}$ (inert from a reactive point of view).

The initial conditions at $t=0$ are the temperature, pressure, and concentration profiles, but their exact nature does not matter because the transient behavior dies down in a small fraction of the conversion timeas observed in the experiments. The boundary conditions are obtained by considering the heat and mass fluxes at the charcoal/atmosphere interface. Radiative transfer was also taken into account. The following boundary conditions for mass and heat transfer are applied:

$$
\begin{aligned}
& -\left.\mathbf{D}_{j \eta}^{*} \cdot \frac{\partial C_{j \eta}}{\partial r}\right|_{r=R_{\mathrm{p}}}=\alpha\left(C_{j \eta}-C_{\infty}\right), \\
& -\left.\lambda_{\eta}^{*} \frac{\partial T_{\eta}}{\partial r}\right|_{r=R_{\mathrm{p}}}=h\left(T_{\eta}-T_{\infty}\right)+Q_{\mathrm{rad}}
\end{aligned}
$$

The mass and heat transfer coefficient values, noted respectively $\alpha$ and $h$, are obtained from classical correlations using Sherwood and Nusselt number, respectively, calculated as described in Appendix A.

\subsection{Numerical methods}

Given the nonlinearity of the problem and the strong coupling existing between the physicochemical processes (transport/energy/kinetic reaction), some iterative numerical schemes and time-splitting methods [29] were needed to avoid a full implicit resolution, expensive in calculation time and not accurate enough.

Thus, the pressure equation, obtained by combining the mass conservation equation, Eq. (5), the Darcy law, Eq. (4), and the ideal gas law, Eq. (9), is solved first. The Picard implicit method is used here to overcome nonlinearity. Once the pressure field is determined, velocity is solved from Eq. (4).

Then, temperature and concentration fields for the different species can be calculated. Species transport equations are solved for the $N$ species; the local mass conservation, $\sum_{j=1}^{N} C_{j \eta}=1$, is thus checked for each node and each time step. If this is not sufficient, the calculation time step (coupled with the reaction characteristic time) is reduced.

A time-splitting method [30], the SSO (sequential split-operator) algorithm, is used to split the transport into a hyperbolic part (convective term) and an elliptic part (diffusive and reaction terms). The convective part is solved using a second-order TVD scheme in space and a first-order explicit Euler scheme in time. The diffusive-reactive part is discretized with a classical implicit scheme. This results in a linear system that is solved using an iterative algorithm like BICGSTAB [31].

At this point, new properties of the medium (particle diameter, porosity, permeability, effective diffusion, and conductivity) can be updated. A quasistationary approach is adopted here to take this evolution into account. It must be emphasized that this is 
valid only if we assume that the interface velocity is low enough, which is currently acceptable for most thermal conversion problems. If the pressure field convergence complies with the accuracy required by the Picard algorithm, then we advance to the next time step. If this is not the case, the pressure field is calculated again until it satisfies the convergence criterion.

\subsection{Calculation of the effective coefficients}

The expressions of the effective coefficients that appear in Eqs. (4)-(8) are obtained from some correlations of the literature $[32,33]$. The effective diffusion coefficient is derived as

$$
\mathbf{D}_{j \eta}^{*}=\frac{\varepsilon_{\eta} D_{j}}{\tau} \text {. }
$$

The values of the specific heat capacity for each species were taken from CHEMKIN tables. The effective conductivity $\lambda_{\eta}^{*}$ is expressed as a function of the temperature [33] and the conversion rate. Rather than using a conductivity model of parallel or series one-dimensional layers representing the different phases, a correlation extracted from Kantorovich and Bar-Ziv [33] is used to predict the effect of transformations of the porous structure during gasification on the thermal conductivity.

We will use the Kozeny-Carman equation to express the relationship between permeability and porosity. The impact of this correlation has been tested and plays a minor role.

Kinetics of steam gasification has been studied extensively by several researchers. The simplest approach suggested is a $n$-order kinetic model [34], but one that is well known to hold for only part of the conversion interval,

$R_{\text {char }}=-k_{1} p_{\mathrm{H}_{2} \mathrm{O}}^{n} \rho_{\eta}$,

where $R_{\text {char }}$ is the reaction term, $k_{1}$ a reaction rate constant, and $p_{\mathrm{H}_{2} \mathrm{O}}$ the partial pressure of steam.

Many authors [35,36] have also derived a Langmuir-Hinshelwood formulation from the writing of elementary reaction steps. The water molecule is adsorbed onto the active sites of the charcoal and then reacts to produce $\mathrm{CO}$ and $\mathrm{H}_{2}$ species, which desorb. The classical expression for such a mechanism is as follows:

$R_{\text {char }}=-\frac{k_{1} p_{\mathrm{H}_{2} \mathrm{O}}}{1+k_{2} p_{\mathrm{H}_{2} \mathrm{O}}} \rho_{\eta}$.

Gadsby et al. [37] first proposed a rate equation taking into account hydrogen inhibition:

$R_{\text {char }}=-\frac{k_{1} p_{\mathrm{H}_{2} \mathrm{O}}}{1+k_{2} p_{\mathrm{H}_{2}}+k_{3} p_{\mathrm{H}_{2} \mathrm{O}}} \rho_{\eta}$.
We will use the relationship introduced by Blackwood and McGrory [38] and adopted by Dasappa et al. [21] in their model:

$R_{\text {char }}=-\frac{k_{1} p_{\mathrm{H}_{2} \mathrm{O}}+k_{4} p_{\mathrm{H}_{2} \mathrm{O}} p_{\mathrm{H}_{2}}+k_{5} p_{\mathrm{H}_{2} \mathrm{O}}^{2}}{1+k_{2} p_{\mathrm{H}_{2}}+k_{3} p_{\mathrm{H}_{2} \mathrm{O}}} \rho_{\eta}$.

The temperature dependence of the parameters $k_{i}$ is described by an Arrhenius law (cf. Appendix B). At this point, a few remarks are necessary. First, it must be emphasized that great uncertainty is found in the literature concerning the expression for the reaction rate $[17,21,22]$. This scattering is due to inherent structural differences in wood and to the pyrolysis process used. Given the predominant influence of reaction kinetics on the gasification curve, it will probably be necessary to fit the activation energy and kinetic parameter values to reproduce the experimental results correctly. We will come back to this point later.

Second, the use of a homogeneous kinetics model, i.e., a reaction rate depending only on the temperature and the partial pressure throughout gasification, does not allow reproducing the charcoal behavior observed experimentally. Indeed, as pointed out in another paper [15], a very marked increase in apparent reactivity is observed, leading to values 10 to 20 times higher than at the beginning of the experiments, although the temperature and the water vapor content remain constant. Many authors [11,12,24,26,39,40] attribute this increase of apparent reactivity to the variation of the reactive surface area (RSA). Under this assumption, within the framework of a surface-related model, Eq. (16) can be expressed as

$R_{\text {char }}=-\mathrm{ks}_{\text {int }} S_{\mathrm{r}} \rho_{\eta}$.

The expression of the intrinsic reactivity is based on the Langmuir-Hinshelwood relationship, given in Eq. (16), as explained previously. If it is admitted today that a relation of proportionality exists between the pore surface area and the reaction rate, the expression of the reactive surface is still a subject of discussion.

Experimental analyzes (BET method, mercury porosimetry) available in the literature are contradictory and it is not possible to conclude at this time on the nature of the surface area that must be considered (macropores or micropores, distribution of active sites). Moreover, several authors have pointed out that particle fracturing, which occurred during the gasification process, created additional reactive surface area together with facilitating the diffusion of the reactant and product gases inside the core of the particles. A few works $[15,34,41]$ consider the catalytic effects of ash in gasification. Other authors [42] 
even argued that surface area and reaction rate are not proportional and suggested using other parameters such as ASA (active surface area) or $\Omega$ (coal moisture holding capacity).

This lack of consensus makes the modeling of charcoal gasification difficult. Some authors overcome this difficulty by introducing a completely empirical two-order polynomial to fit their models [17]. A review of different approaches, usually more or less empirical, used in the literature to describe the charcoal gasification rate can be found in other works $[43,44]$. Several models, in particular, use the theory of evolution of surface area developed by Bhatia and Vartak [45], based on a discrete random pore model. This theory takes into account the competitive mechanisms of surface area increase and overlapping of pores. If this approach leads to some good results for graphite and coal chars, for which the apparent reactivity decreases with increasing conversion and exhibits a maximum, it does not suit biomass chars. As emphasized by Dasappa et al. [7] from the observation of SEM pictures, indeed, the microscopic structures of wood and coal chars are very different. Wood chars present a remarkably regular structure similar to a beehive network, whereas the coal chars are characterized by highly random structures due to their origin. This contrast makes the random pore theory less relevant to biomass char gasification. Experimental measurements of the RSA of beechwood char as a function of the degree of conversion, carried out by Klose and Wolki [40] using the temperature-programmed desorption technique, supports this assumption. Their surface area increases constantly as a function of conversion throughout gasification. A similar observation is also made by Lussier et al. [46]. Both adsorbed hydrogen concentration $\left(\mathrm{mol}_{\mathrm{H}} \mathrm{g}_{\mathrm{char}}^{-1}\right.$ ) and charcoal reactivity per unit area remain constant during conversion from 0.5 to $40 \%$. Two scenarios are proposed to explain this phenomenon (it was not possible to distinguish between them): either the distribution of active sites is unchanged in spite of the modification in the charcoal structure, or increasing surface area-i.e., increasing the concentration of active sites-with conversion coincidentally compensates for the decrease of reactivity as reactive carbon is consumed.

On the basis of this discussion, we adopt this approach in this study and assume that the reactive surface $S_{\mathrm{r}}$ increases so that the term $S_{\mathrm{r}} \rho_{\eta}$, and hence the reaction term $R_{\text {char }}$, remains constant throughout gasification until the moment when the entire structure collapses suddenly.

Following this hypothesis, the reactive surface $S_{\mathrm{r}}(t)$ is related to the porosity $\varepsilon$ (or to the degree of

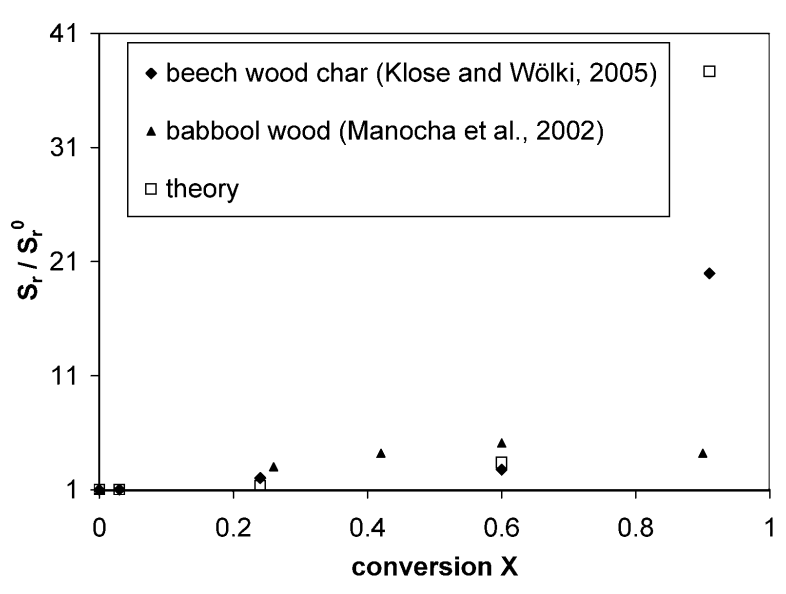

Fig. 11. Variation of charcoal surface area during gasification (theory and literature).

conversion $X$ ) by

$\frac{S_{\mathrm{r}}(t)}{S_{\mathrm{r}}^{0}}=\frac{1-\varepsilon_{\eta}^{0}}{1-\varepsilon_{\eta}}=\frac{1}{1-X}$.

The comparison between theoretical and experimental variation of surface area with conversion is presented in Fig. 11. It is remarkable that such a crude formulation succeeds in quasi-perfectly recovering up to around $60 \%$ of conversion all the complexity of physical mechanisms involved in the RSA evolution.

It must be noted that the classical model of capillary tubes does not hold in this case. Indeed, with the assumption of long cylindrical pores of radius $r_{\mathrm{P}}$, porosity and surface area per unit volume are linked as follows:

$\varepsilon_{\eta}=S_{\mathrm{r}} \frac{r_{\mathrm{P}}}{2}$.

Assuming that the pores grow by radial expansion, Eq. (19) leads to the following relationship, which is very different from Eq. (18):

$\frac{S_{\mathrm{r}}(t)}{S_{\mathrm{r}}^{0}}=\sqrt{\frac{\varepsilon_{\eta}}{\varepsilon_{\eta}^{0}}}$.

Actually, the aforementioned approach corresponds to an increase of the surface area due to the evolution of macropores (i.e., capillary tubes), whereas our formulation is based on the development of micropores located on the tube walls.

The code has been programmed in FORTRAN and the numerical simulations have been performed on a Pentium IV, $3.2 \mathrm{GHz}$. The calculation times depend on the operating conditions (particle size in particular) and vary between 3 and $10 \mathrm{~min}$. Moreover, the use of the local thermal equilibrium assumption, discussed further, decreases a little these calculation times. As a consequence, this model suits perfectly as a submodel in CFD simulations of big gasifiers. 


\section{Numerical results and discussion}

\subsection{Impact of operating conditions: comparison with experiments}

The numerical model is confronted with the experimental results, detailed in the previous section, obtained for a single charcoal particle suspended in a macro-TG reactor and gasified in an atmosphere of $\mathrm{H}_{2} \mathrm{O}-\mathrm{N}_{2}$ mixture.

As described above, experiments were carried out with previously pyrolyzed wood particles of different diameters (in the following, particles will be referenced by their initial size before pyrolysis-10, 20, or $30 \mathrm{~mm}$-in order to simplify the notation). It must be emphasized that these particles after pyrolysis are no longer spherical (variation of 10 to $15 \%$ with respect to the mean diameter), which introduces a supplementary problem within the modeling. A mean diameter was used for our simulations. Nevertheless, it must be noted that the assumption of a charcoal particle that remains spherical throughout gasification could explain certain discrepancies observed between numerical and experimental results.

Given the uncertainty in the literature around the expression of the reaction rate, the first step consisted in fitting the reaction parameters to reproduce the experimental curves correctly. The obtained values of kinetic parameters are given in Appendix B, together with the physical and chemical constants used in the simulations.

Then, different simulations were performed varying charcoal diameter, temperature, steam partial pressure, and gas injection velocity; the comparison with the experimental results is given in Figs. 12-15. We have represented here the variation of the degree of conversion $X$ as a function of time.

\subsubsection{Particle diameter}

We deal with the gasification of three particles, of initial diameter 10,20 , and $30 \mathrm{~mm}$, respectively, at $T=930^{\circ} \mathrm{C}$ and $p_{\mathrm{H}_{2} \mathrm{O}}=0.2 \mathrm{~atm}$. Steam is injected at a velocity of $0.14 \mathrm{~m} \mathrm{~s}^{-1}$. Comparison between experiments and simulation results is presented in Fig. 12.

The gasification rate increases as particle size decreases, which confirms the internal transfer effects. Even for diameter of $7.05 \mathrm{~mm}$ (corresponding to an average diameter of $10 \mathrm{~mm}$ before pyrolysis), the impact of internal transfers is weak but not negligible. The minimal particle size to overcome diffusive effects, i.e., the size below which the gasification rate is constant, was estimated from simulations around $1 \mathrm{~mm}$. This result corresponds with those found in the literature, between the value predicted by Dasappa et al. [7], $200 \mu \mathrm{m}$, and that of Ergun [47], $1.8 \mathrm{~mm}$.

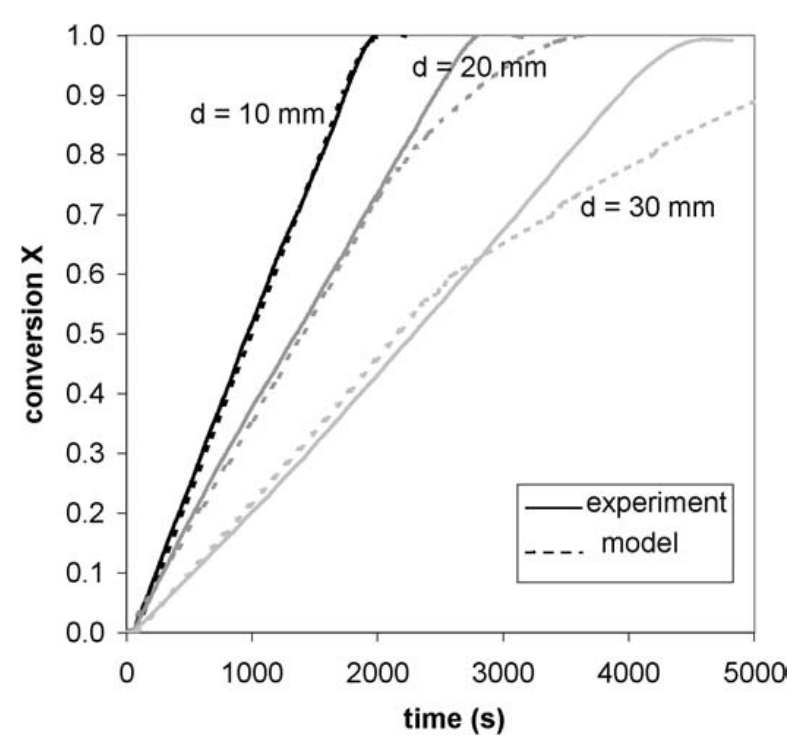

Fig. 12. Influence of particle diameter on conversion $\left(T=930^{\circ} \mathrm{C}, P_{\mathrm{H}_{2} \mathrm{O}}=0.2 \mathrm{~atm}\right)$.

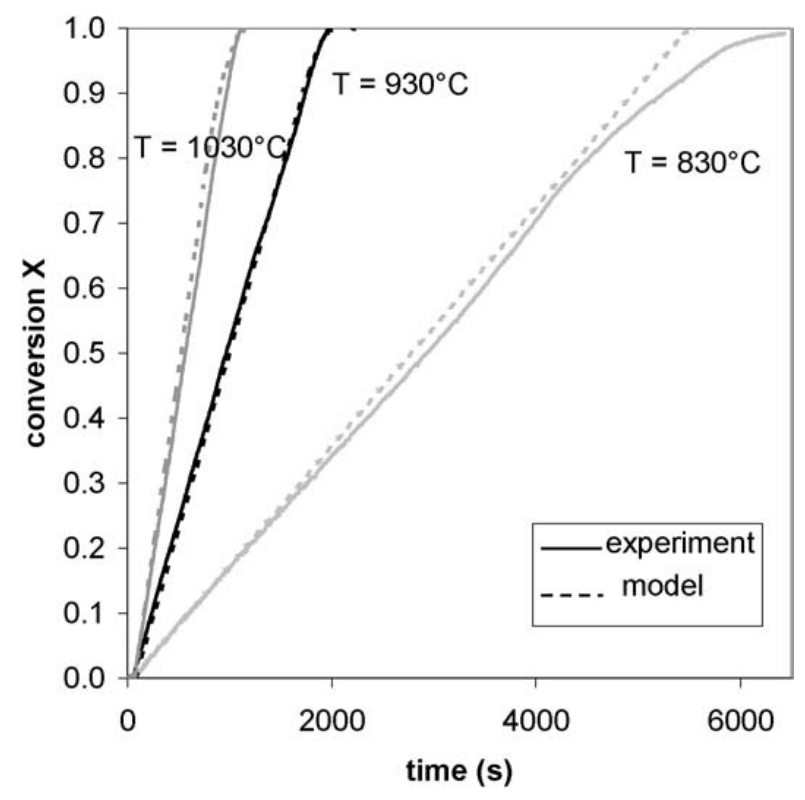

Fig. 13. Influence of temperature on conversion $(d=10 \mathrm{~mm}$, $\left.P_{\mathrm{H}_{2} \mathrm{O}}=0.2 \mathrm{~atm}\right)$.

At low conversion rates, up to $60 \%$ if we consider all curves, the calculated values accurately match the experimental results. Nevertheless, when the conversion rate increases and the particle size also, the model does not succeed in reproducing the linear evolution observed experimentally during gasification. It overestimates the influence of the internal transfers for large particles. Indeed, since an excellent agreement is obtained for the $10-\mathrm{mm}$ particle where the impact of internal transfers is weak, the discrepancy observed cannot be due to the reaction kinetics. It must be emphasized that this relative lack of accuracy beyond a critical value of conversion is not specific to this model. To our knowledge, no model available in the literature succeeds in completely predict- 


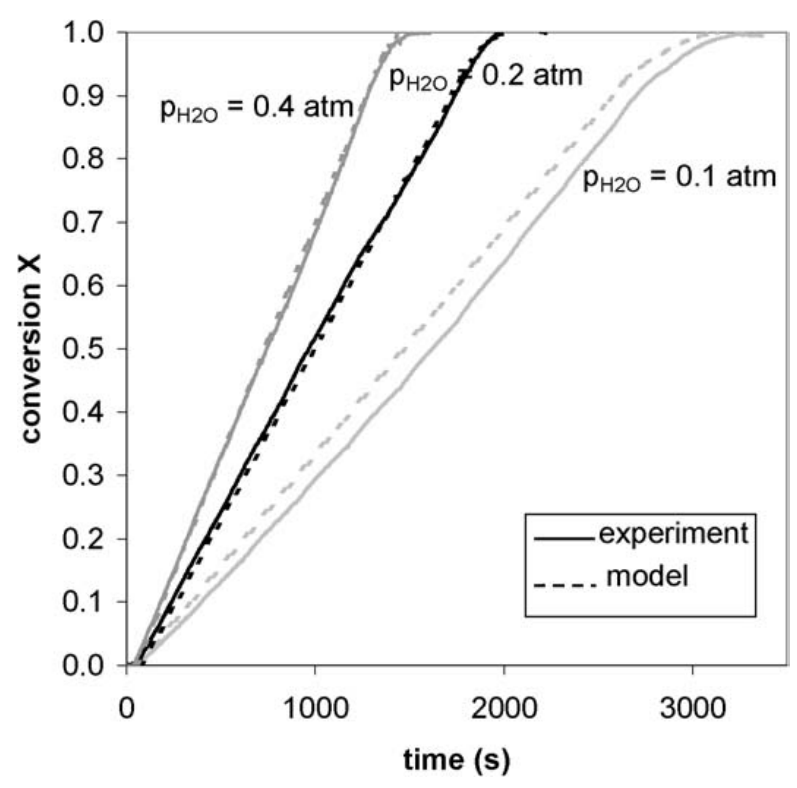

Fig. 14. Influence of steam partial pressure on conversion $\left(d=10 \mathrm{~mm}, T=930^{\circ} \mathrm{C}\right)$.

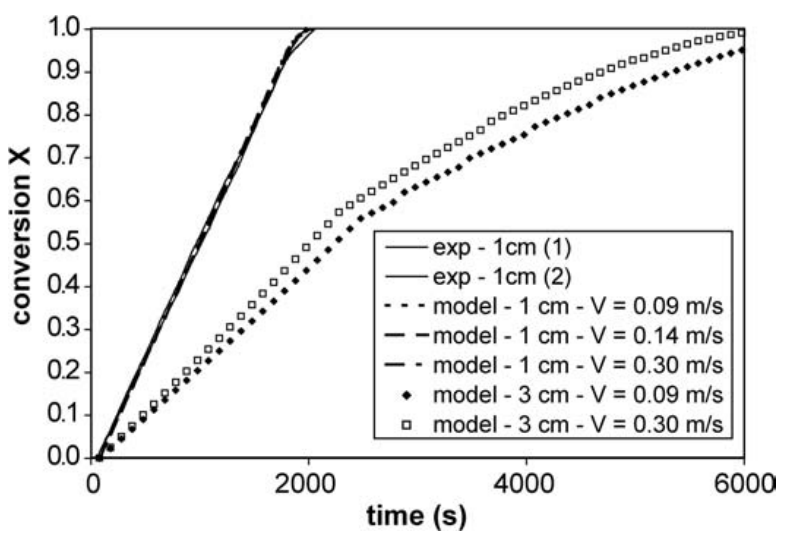

Fig. 15. Influence of gas injection velocity on conversion $\left(d=10\right.$ and $\left.30 \mathrm{~mm}, P_{\mathrm{H}_{2} \mathrm{O}}=0.2 \mathrm{~atm}, T=930^{\circ} \mathrm{C}\right)$.

ing biomass charcoal behavior throughout gasification. A similar conclusion is made by Struis et al. [28]. Dasappa et al. [7], for example, also present a comparison between predictions and experiments valid only up to a conversion of $60 \%$.

Several reasons can be proposed to explain this discrepancy. First, it must be remembered that the model is a spherically symmetric one-dimensional model, based on the assumption of an isotropic material. But, as the wood is anisotropic, it loses its initial shape during gasification and shrinks more in the transversal direction (cf. Figs. 5 and 6). This shorter dimension facilitates mass and heat transfers inside the particle in comparison with the predictions of the model. As a consequence, if this assumption is relevant at low conversion, i.e., before the particle size decreases, at the end of the gasification process it leads to an overestimate of $\mathrm{d} X / \mathrm{d} t$.

Moreover, several authors [5,28,48] have suggested that such behavior could result from peripheral fragmentation, i.e., the disintegration of the porous charcoal into small fragments at the particle surface. This above-mentioned phenomenon can be seen as a percolative fragmentation process. The gasification process leads to the disappearance of the solid phase, described by Eq. (6), and the formation of a porosity gradient due to the mass transfer effects, until the local porosity of the superficial slice of the particle reaches a critical value $\varepsilon_{\eta}^{*}$. At this point, the charcoal structure disintegrates at the surface and the particle radius decreases. A possible explanation is that when too much carbon has been removed from the charcoal structure, the remaining matrix cannot stand by itself and detaches from the particle, taking away the remaining carbon at this location.

An attempt to take into account this phenomenon in gasification models has been undertaken by Wang and Bhatia [48] through the assumption of a critical porosity for fragmentation. However, their approach remains limited to uniform peripheral fragmentation in order to keep a 1D model. It also neglects the formation of fractures inside the particle, which can play the role of highly conductive channels and speed up the gasification process. Finally, results strongly depend on the choice of $\varepsilon_{\eta}^{*}$ and, consequently, are still qualitative and not validated experimentally yet.

To test this assumption, we varied the value of $\varepsilon_{\eta}^{*}$ for a particle of initial diameter $30 \mathrm{~mm}$ and compared the model predicted evolution of the particle's outside radius and of the conversion with experimental measurements, illustrated in Fig. 6. We plotted these comparisons in Figs. 16 and 17 when $\varepsilon_{\eta}^{*}$ values of $0.999,0.9$, and 0.8 were considered.

At first sight, when looking at Figs. 16 and 17, the optimum value seems to be $\varepsilon_{\eta}^{*}=0.9$. Actually, this approach raises a problem for smaller particles. Their radius decreases later as observed experimentally (around $80-90 \%$ of conversion) and the introduction of such an assumption accelerates the conversion too much (cf. Fig. 17). This difficulty is not mentioned by Wang and Bhatia [48]. A more relevant criterion for fragmentation could be the porosity gradient. Indeed, a porosity gradient may induce mechanical constraints explaining the detachment of the surface, and hence, such a criterion would make it possible to get rid of the considered particle size. Finally, a reasonable fit between experiments and the model is obtained if fragmentation is not performed (when $\varepsilon_{\eta}=1$ ). For numerical purposes, the criterion which is used for all the simulations was $\varepsilon_{\eta} \geqslant 0.999$. Removing the ash at this stage-according to the model-has no impact on the time evolution of the degree of conversion.

Consequently, in the case of the present experiments, where the particles are not submitted to mechanical constraints (but the flow of atmosphere gas 


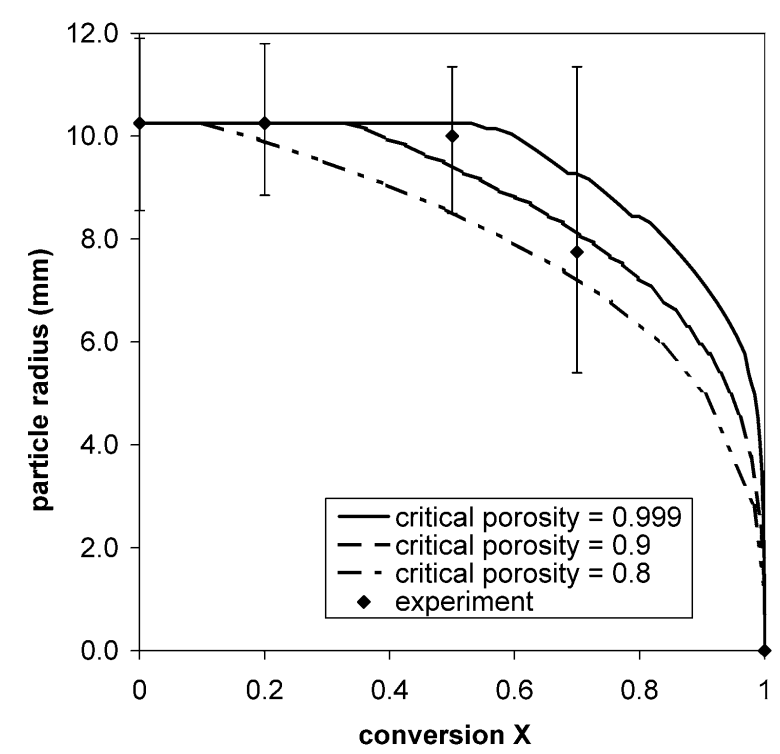

Fig. 16. Impact of peripheral fragmentation on particle radius evolution during gasification (initial diameter $30 \mathrm{~mm}$, $\left.T=930^{\circ} \mathrm{C}, P_{\mathrm{H}_{2} \mathrm{O}}=0.2 \mathrm{~atm}\right)$.

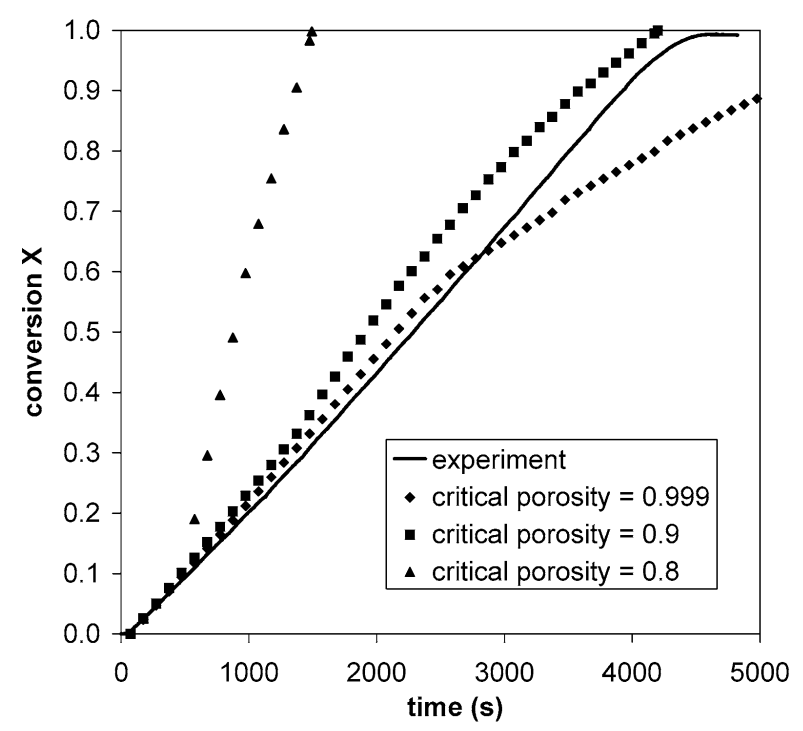

Fig. 17. Impact of peripheral fragmentation on conversion (initial diameter $30 \mathrm{~mm}, T=930^{\circ} \mathrm{C}, P_{\mathrm{H}_{2} \mathrm{O}}=0.2 \mathrm{~atm}$ ).

around it), ash removal occurs late in the process. In contrast, in the case of a particle inside a fixed bed, each particle will be submitted to strong mechanical constraints, due to the weight of the bed above it, and to particle mixing resulting from the continuous feed; these constraints increase as the particle goes down the bed and is gasified. In this case, it is likely that peripheral fragmentation will start earlier and will affect the outside diameter of the particle. Whatever the diameter of the considered particle, the model developed here indicates that the time for full gasification is reduced by approximately $35 \%$ if fragmentation is performed at $\varepsilon_{\eta}^{*}=0.9$, and reduced by $80 \%$ if it is performed at $\varepsilon_{\eta}^{*}=0.8$. Consequently, peripheral fragmentation may become a dominant factor in the prediction of the particle gasification process.

Similarly, Struis et al. [28] add that an exposure of fresh surface area, i.e., a specific increase of the considered reactive surface area, accompanies the particle disintegration process. This assumption seems plausible since the departure of the results starts with particle size reduction.

This increase of the surface area can be linked also to the appearance of fractures, a feature not modeled in the present analysis, which penetrate to the core of the charcoal as suggested by the observation of tomography pictures (cf. Fig. 9). These fractures play the role of highly conductive channels facilitating mass and heat transfer inside the particle. Their effect is particularly obvious if we look carefully at the curve for the $3-\mathrm{cm}$ charcoal where we note an acceleration of the gasification rate (nonlinear slope) around $60 \%$ of conversion.

Nevertheless, it must be remembered that the final objective of this study is the choice of simplifying assumptions within the development of a fixedbed model. Given mechanical stresses encountered in gasifiers, which increase this fragmentation phenomenon, this assumption of neglecting fracture formation seems to be perfectly relevant.

\subsubsection{Temperature}

The gasification rate increases when the temperature increases, as illustrated by simulations at 830 , 930, and $1030^{\circ} \mathrm{C}$ (cf. Fig. 13). Simulations are performed for a $10-\mathrm{mm}$-diameter particle placed in an atmosphere with a steam partial pressure of $0.2 \mathrm{~atm}$ and with an injection velocity of $0.14 \mathrm{~m} \mathrm{~s}^{-1}$. The sensitivity of the gasification process to the temperature is correctly recovered by the model. The results presented below support the choice of kinetic and activation energy values used for the model.

\subsection{3. $\mathrm{H}_{2} \mathrm{O}$ partial pressure}

Simulation results for gasification of charcoal under steam partial pressures of $0.1,0.2$, and 0.4 atm are illustrated in Fig. 14. Operating conditions correspond to the 10 -mm-diameter particle, a temperature of $930^{\circ} \mathrm{C}$, and an injection velocity of $0.14 \mathrm{~m} \mathrm{~s}^{-1}$.

When looking at the curves, we note good agreement between the model and experiments, even if discrepancy is slightly greater at low partial pressure. However, this remains confined to the confidence interval of experimental curves. This figure supports the choice of the kinetic scheme (Eq. (16)).

\subsubsection{Gas injection velocity}

The impact of the gas injection velocity was also tested. Simulations were performed at three different velocities, respectively at $0.09,0.14$, and $0.30 \mathrm{~m} / \mathrm{s}$, 
Table 3

Numerical data for the simulation

\begin{tabular}{llll}
\hline$d(\mathrm{~cm})$ & $V_{\mathrm{inj}}\left(\mathrm{m} \mathrm{s}^{-1}\right)$ & $T\left({ }^{\circ} \mathrm{C}\right)$ & $C_{\mathrm{H}_{2} \mathrm{O}}$ \\
\hline 2 & 0.14 & 900 & 0.138 \\
\hline
\end{tabular}

for a $10-\mathrm{mm}$ particle gasified at $930{ }^{\circ} \mathrm{C}$ under a steam partial pressure of $0.2 \mathrm{~atm}$. Three curves obtained, as illustrated in Fig. 15, are practically confounded and all included in the range of experimental curves. As explained before, this range corresponds to the error interval of the reference experiment. These simulations confirm that gas velocity has no effect on gasification under these experimental conditions. External transfers are reaction-limiting (assumption confirmed by the concentration field analysis in the following section), but diffusion effect is widely predominant over convective effect in the case of a $10-\mathrm{mm}$ particle (Nusselt and Sherwood numbers vary respectively between 2.764 and 3.446 and between 2.487 and 2.922).

However, as expected, the gas injection velocity becomes a nonnegligible parameter as the particle size increases. The impact of gas velocity on the gasification of a $30-\mathrm{mm}$ particle at $T=930^{\circ} \mathrm{C}$ and $p_{\mathrm{H}_{2} \mathrm{O}}=0.2 \mathrm{~atm}$ is illustrated in Fig. 15. This impact will be all the more obvious in the fixed-bed gasifier as the injection velocity is greater (typically between 1 and $3 \mathrm{~m} \mathrm{~s}^{-1}$ ).

\subsection{Gasification of a single particle: fields analysis}

In this section we present the different fields obtained within the model for gasification of a single particle. Since the computational model reproduces the experimental data with sufficient accuracy, it is interesting to use it for analyzing what is going on inside the particle. Operating conditions considered here correspond to average conditions. The numerical data and boundary conditions of the problem are summarized in Table 3 . The initial radius of the particle is the radius after pyrolysis. The $\mathrm{H}_{2} \mathrm{O}$ mass fraction imposed here corresponds to a steam partial pressure of 0.2 atm.

Fields of temperature, variation of pressure, $\mathrm{H}_{2} \mathrm{O}$ and $\mathrm{H}_{2}$ mass fraction, and porosity are presented as a function of the dimensionless radius for two different times, $t=2000 \mathrm{~s}(X=0.45)$ and $t=4000 \mathrm{~s}$ $(X=0.80)$, in Figs. 18-20. The dimensionless radius is calculated from the charcoal radius at the given time, respectively 2000 and $4000 \mathrm{~s}$. The evolution of the particle size during conversion of the charcoal is also shown in Fig. 20.

At first, simulations confirmed that internal transfers limit the reaction. Indeed, for the range of particle diameters from 7 to $21 \mathrm{~mm}$, observation of porosity fields proved that the gasification process can follow
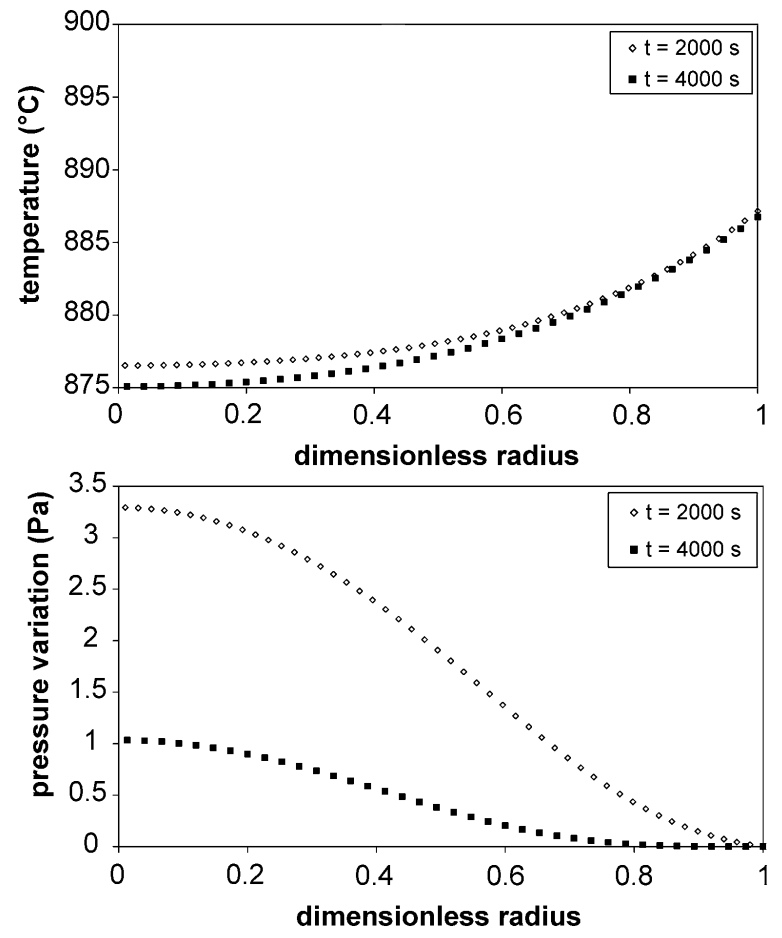

Fig. 18. Fields of temperature and pressure variation inside the particle during gasification for $t=2000 \mathrm{~s}$ and $t=4000 \mathrm{~s}$ (char particle diameter $20 \mathrm{~mm}, T=900^{\circ} \mathrm{C}$, $\left.P_{\mathrm{H}_{2} \mathrm{O}}=0.2 \mathrm{~atm}\right)$.

neither a reacting-core model (isoconversion) nor a shrinking-core model.

Looking at the curves in Fig. 20, we can notice an increase of the porosity during gasification. Permeability being directly linked with the porosity value, the internal pressure also decreases. This porosity variation leads to a decrease in limitation by internal transfers, as we can see in Fig. 19 from the evolution of steam concentration (slope of the curve is less pronounced at $t=4000 \mathrm{~s}$ than at $t=2000 \mathrm{~s}$ ).

Conversely, hydrogen production and steam consumption do not vary during particle conversion, since the increase of reactive surface area compensates for the loss of charcoal mass. For the same reason, the temperature decrease, observed in Fig. 18, due to the endothermic nature of the steam/charcoal reaction, remains quasi constant throughout time. These results emphasize the great complexity of the phenomenon and the coupling between different physical processes involved.

The curve also suggests a late evolution of particle radius during conversion, beyond a conversion rate of 0.6-0.7. This result is in agreement with experimental measures presented in Fig. 6 and the simulation of Dasappa et al. [7].

Finally, the effect of external transfers on gasification must be noted. Fig. 19 shows the discrepancy between $\mathrm{H}_{2} \mathrm{O}$ concentration at the surface, $C_{\mathrm{H}_{2} \mathrm{O} \eta}^{\mathrm{surf}}$, equal to 0.07 , and the bulk concentration, 0.138 . 

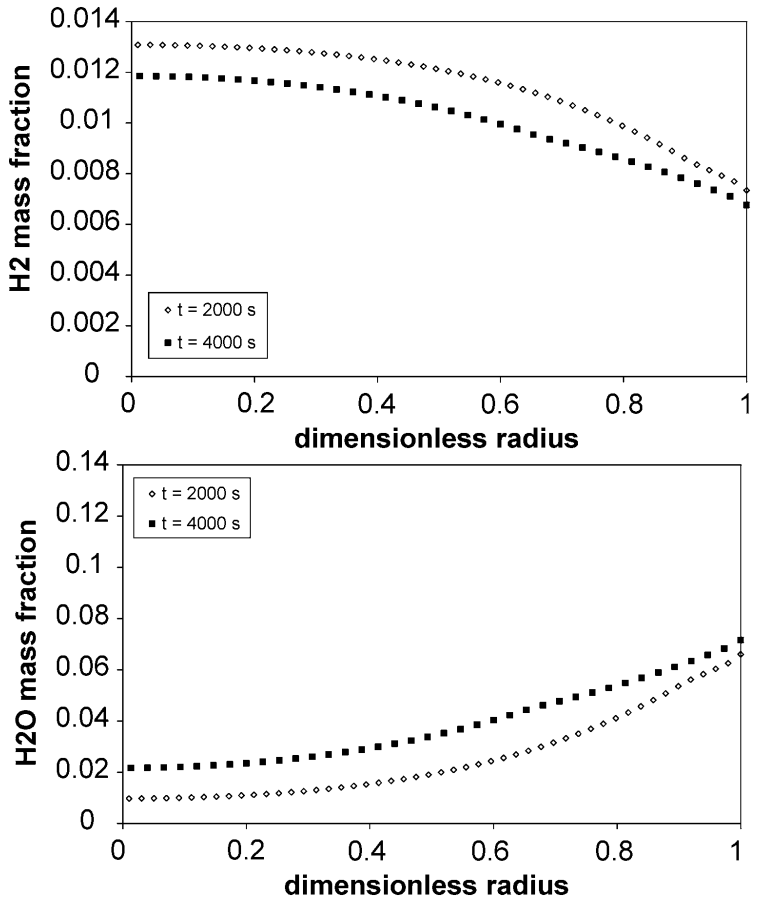

Fig. 19. Fields of $\mathrm{H}_{2}$ and $\mathrm{H}_{2} \mathrm{O}$ mass fraction inside the particle during gasification for $t=2000 \mathrm{~s}$ and $t=4000 \mathrm{~s}$ (char particle diameter $20 \mathrm{~mm}, T=900^{\circ} \mathrm{C}, P_{\mathrm{H}_{2} \mathrm{O}}=0.2 \mathrm{~atm}$ ).

A similar remark can be made concerning the temperature field in Fig. 18, with a difference around of $13 \mathrm{~K}$ between the temperature at the surface and the bulk temperature. This discrepancy remains quasi-constant throughout gasification. Indeed, let us consider the species transport equation, Eq. (7). If we assume a quasi-steady approach and neglect convective flux for diffusive flux, we obtain

$$
\nabla \cdot\left(\rho_{\beta \eta} \mathbf{D}_{\mathrm{H}_{2} \mathrm{O} \eta}^{*} \cdot \nabla C_{\mathrm{H}_{2} \mathrm{O} \eta}\right)+R_{\mathrm{H}_{2} \mathrm{O} \eta}=0 .
$$

After integration of the particle volume and using the boundary condition equation (10), we obtain

$C_{\mathrm{H}_{2} \mathrm{O} \eta}^{\text {surf }}=C_{\infty}-\frac{\left\langle R_{\mathrm{H}_{2} \mathrm{O} \eta}\right\rangle V_{\eta}}{\alpha \rho_{\beta \eta} S_{\eta}}$,

where $\left\langle R_{\mathrm{H}_{2} \mathrm{O} \eta}\right\rangle$ is the averaged reaction term and $V_{\eta}$ and $S_{\eta}$ are respectively the volume and the outside surface of the particle. Equation (22) could be verified with the value of the parameters extracted from the simulations. Hence, we recover quasi-perfectly the value of $C_{\mathrm{H}_{2} \mathrm{O} \eta}^{\mathrm{surf}}$ observed numerically. Finally, all the other parameters remaining quasi constant, $C_{\mathrm{H}_{2} \mathrm{O} \eta}^{\text {surf }}$ varies only as a function of the ratio $V_{\eta} / S_{\eta}$, i.e., as a function of the charcoal size. A similar demonstration holds for heat transfer.

\subsection{Relevance of the assumptions of local mass equilibrium and local thermal equilibrium}

The assumption of local mass or thermal equilibrium between a particle and the surrounding gas phase
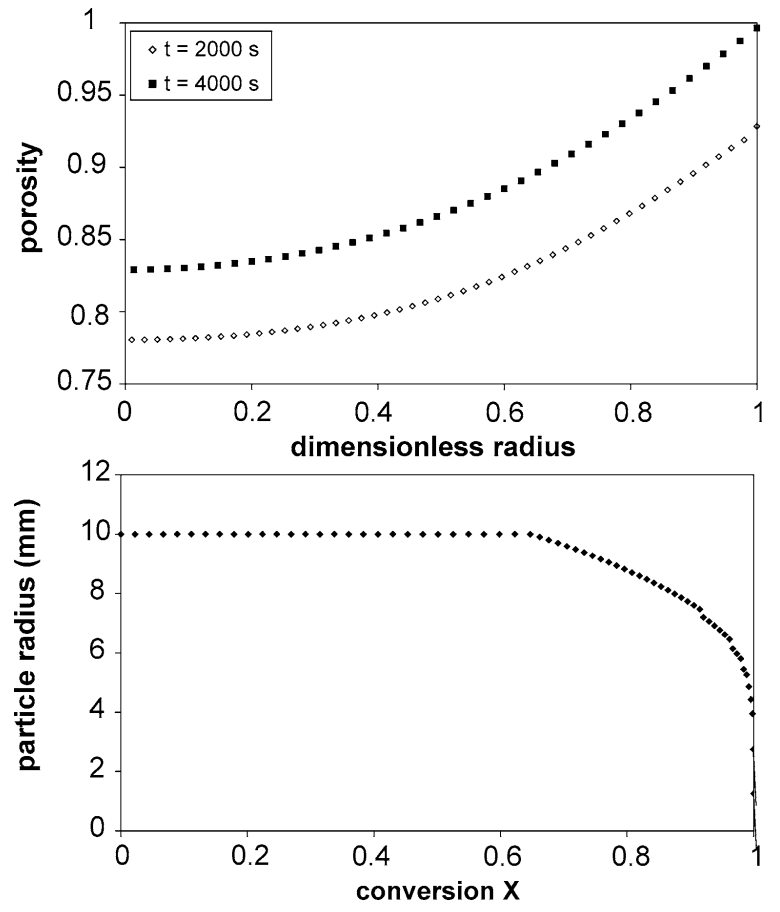

Fig. 20. Porosity field during gasification at $t=2000 \mathrm{~s}$ and $t=4000 \mathrm{~s}$ and evolution of the particle radius as a function of the degree of conversion (char particle diameter $20 \mathrm{~mm}$, $\left.T=900^{\circ} \mathrm{C}, P_{\mathrm{H}_{2} \mathrm{O}}=0.2 \mathrm{~atm}\right)$.

reveals of primordial interest within the framework of the development of an averaged model at fixed-bed scale. A few comments are necessary at this point. Let us consider the derivation of a macroscopic model for mass transfer at the reactor scale using the volumeaveraging method [49]. A similar comment will hold for the heat transfer.

Briefly, upscaling is conducted by forming spatial averages over an averaging volume denoted $V$. Intrinsic averages for concentration of species $j$ can thus be defined for each phase, the char-phase denoted $\eta$ and the surrounding gas-phase denoted $\omega$, as follows:

$$
\begin{aligned}
& \left\langle C_{j \eta}\right\rangle^{\eta}=\frac{1}{V_{\eta}} \int_{V_{\eta}} C_{j \eta} \mathrm{d} V ; \\
& \left\langle C_{j \omega}\right\rangle^{\omega}=\frac{1}{V_{\omega}} \int_{V_{\omega}} C_{j \omega} \mathrm{d} V .
\end{aligned}
$$

Here $V_{\eta}$ (resp. $V_{\omega}$ ) is the volume of the $\eta$-phase (resp. $\omega$-phase) contained in the averaging volume $V$. With these definitions and the spatial averaging theorem [50], one can derive reactor-scale averaged equations by applying averaging operators to the Darcy-scale conservation equations posed by Eqs. (4)-(9). This formulation is called the two-equation nonequilibrium model or double-porosity model. The reader can refer to Ahmadi et al. [51] for more details about this development.

However, it is not difficult to imagine circumstances in which the characteristic time for transport 
(a)
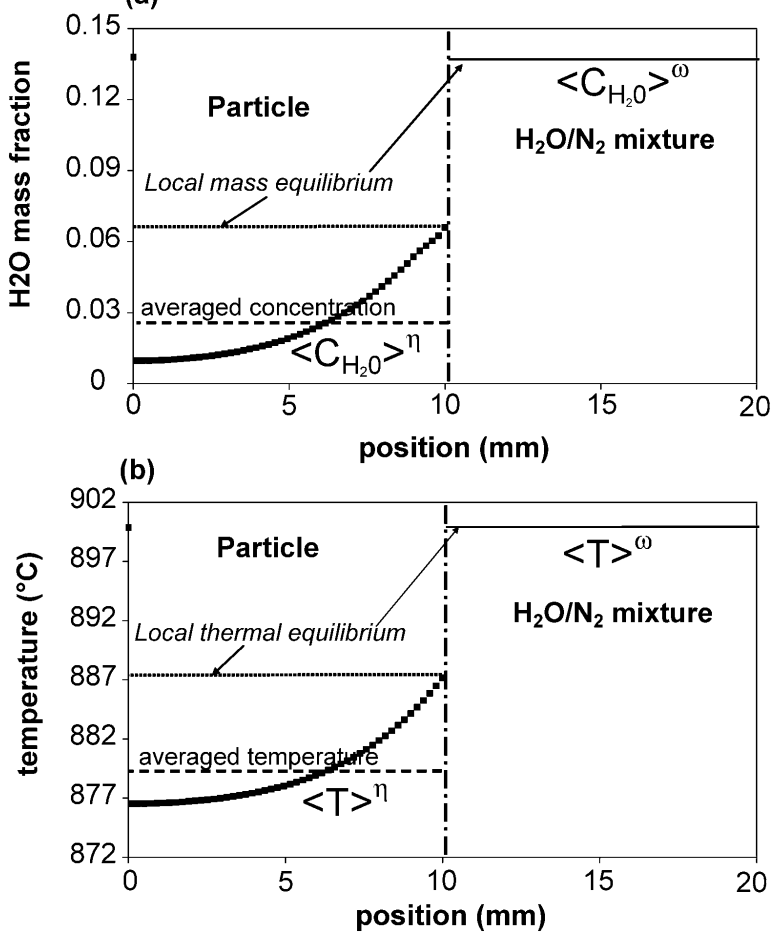

Fig. 21. Illustration of the assumption of local mass equilibrium (a) and local thermal equilibrium (b) during gasification.

in the fluid phase is great in relation to the characteristic time for transport within the charcoal. Under such circumstances, a one-equation model may be valid for describing the reactive transport problem.

Under conditions of thermodynamic equilibrium, Eq. (24) indicates that the average concentrations are related by

$\left\langle C_{j \eta}\right\rangle^{\eta}=K_{j, \mathrm{eq}}\left\langle C_{j \omega}\right\rangle^{\omega}$,

at thermodynamic equilibrium.

Even when the condition of thermodynamic equilibrium does not exist, Eq. (24) can be used as a reasonable approximation. When this occurs, we say that the condition of local mass equilibrium is valid. Under these circumstances, the concentrations associated to each phase predicted by the two-equations model are tied to one another, and these equations can be added together to produce an one-equation expression describing solute transport.

Based on the development obtained in Eq. (22), we may consider that concentration and temperature at the particle surface are quasi-constant during the gasification process and define a $K_{j \text {,eq. What about }}$ the local mass (and thermal) equilibrium assumption? Fig. 21 illustrates the problematic involved.

In order to test whether these simplifying assumptions are pertinent or not, two simulations were performed, either keeping steam concentration constant

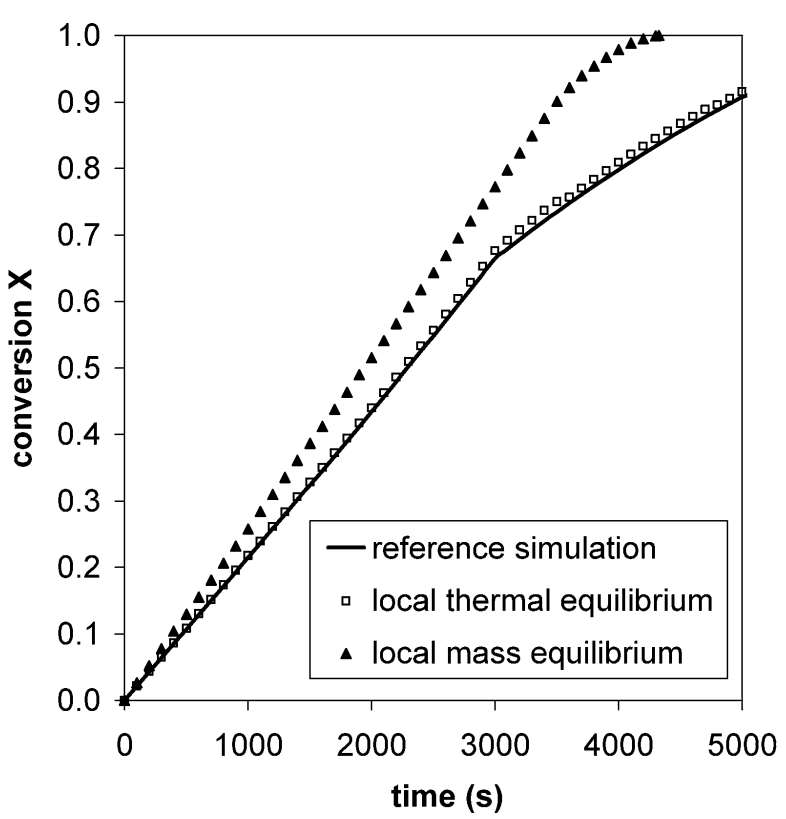

Fig. 22. Impact of local mass equilibrium and thermal equilibrium assumption on conversion (char particle diameter $\left.20 \mathrm{~mm}, T=900^{\circ} \mathrm{C}, P_{\mathrm{H}_{2} \mathrm{O}}=0.2 \mathrm{~atm}\right)$.

inside the particle and equal to the surface concentration $C_{\mathrm{H}_{2} \mathrm{O} \eta}^{\text {surf }}$ (local mass equilibrium), or keeping temperature constant inside the particle and equal to the surface temperature $T_{\eta}^{\text {surf }}$ (local thermal equilibrium). Numerical data for simulations are extracted from Table 3. Comparison of both approaches with the reference simulation is presented in Fig. 22.

As expected, the assumption of local mass equilibrium does not hold, which confirms that a reactingcore model cannot be applied to the gasification process. In contrast, the isothermal model corresponding to an assumption of local thermal equilibrium at the reactor-scale leads to an excellent approximation of the phenomenon. A discrepancy of only $2 \%$ versus the reference simulation is observed, at least in the range of operating conditions studied. This approach can present a great interest within the framework of fixed-bed modeling, for the choice of simplifying assumptions.

\section{Conclusions and perspectives}

A numerical model based on balance equations for gas species and enthalpy, and including heterogeneous reaction kinetics, was developed. It is able to retrieve, both qualitatively and quantitatively with an accuracy of $7 \%$ until $60 \%$ of conversion, the effect of the parameters that can be controlled in an industrial process of gasification of large particles by $\mathrm{H}_{2} \mathrm{O}$ : the diameter of the particle (10-30 mm), the temperature $\left(830-1030{ }^{\circ} \mathrm{C}\right)$, and the $\mathrm{H}_{2} \mathrm{O}$ partial pressure $(0.1-$ $0.4 \mathrm{~atm}$ ) of the surrounding gas phase. The confronta- 
tion with a set of accurate experiments-including repeatability tests - made it possible to determine the kinetic parameters to describe carbon conversion by $\mathrm{H}_{2} \mathrm{O}$ and inhibition by $\mathrm{H}_{2}$.

During experiments under all conditions, the conversion follows an almost linear evolution with time. The model can describe this in the case of small particles where reaction kinetics is dominant, but fails to describe the conversion of larger particles beyond $60 \%$ conversion. The origin of this discrepancy remains problematic. Several phenomena, such as the assumption of a spherically symmetric model, large fracture formation, or peripheral fragmentation, can be proposed as explanations. In this conversion domain, mechanical phenomena can be predominant, and models based upon balance equations are no longer valid. Peripheral fragmentation strongly depends on the process, and cannot be included in a model at particle scale.

The model once validated made it possible to characterize the thermochemical situation. Obtained results confirm that the use of simplified approaches such as a homogeneous or shrinking-core model is not satisfying. Mass transfer is limiting the process for large particles both outside and inside; the assumption of mass equilibrium between the particle and the surrounding gas is not valid. On the other hand, the assumption of thermal equilibrium between the particle and the surrounding gas can be adopted with minor impact, and will simplify the development of a model at fixed-bed scale.

The final objective of this study, indeed, is to support the design of a 1.5-MW fixed-bed gasifier, implemented on an existing natural-gas-fired CHP plant in Gjøl (Denmark), within the framework of the Lift Off European project. Based on the results presented here, a model for the gasification of wood char in a continuously fed fixed-bed reactor is being developed.

The choice of a large-scale model, so-called mixed formulation, has been adopted. A rigorous theoretical formulation is being developed within the volume averaging method. It will couple a macroscopic representation for the gas phase with a fine microscopic description for the char phase.

\section{Acknowledgments}

The research was partly funded by the European Commission in the framework of 5th Programme, contract NNE5/2001/704 and the French Environment and Energy Management Agency (ADEME). This work was carried out by the following partners: CIRAD, Gjoel, NTUA, FORCE Technology, EMAC, and TK Energi A.S.

\section{Appendix A. Equations of the model}

The underlying equations of the model are recalled in this appendix:

$$
\begin{aligned}
& \nabla P_{\eta}=-\mu \mathbf{K}_{\eta}^{-1} \cdot \mathbf{V}_{\eta} \\
& \frac{\partial\left(\varepsilon_{\eta} \rho_{\beta \eta}\right)}{\partial t}+\nabla \cdot\left(\rho_{\beta \eta} \mathbf{V}_{\eta}\right)=\sum_{j=1}^{n} R_{j \eta}, \\
& \frac{\partial \varepsilon_{\eta}}{\partial t}=\frac{1}{\rho_{\sigma \eta}} \sum_{j=1}^{n} R_{j \eta} \\
& \underbrace{\frac{\partial\left(\varepsilon_{\eta} \rho_{\beta \eta} C_{j \eta}\right)}{\partial t}}_{\text {accumulation }}+\underbrace{\nabla \cdot\left(\rho_{\beta \eta} \mathbf{V}_{\eta} C_{j \eta}\right)}_{\text {convection }} \\
& =\underbrace{\nabla \cdot\left(\rho_{\beta \eta} \mathbf{D}_{j \eta}^{*} \cdot \nabla C_{j \eta}\right)}_{\text {diffusion }}+\underbrace{R_{j \eta}}_{\text {reaction }},
\end{aligned}
$$

$\underbrace{\left(\rho C_{\mathrm{P}}\right)_{\eta} \frac{\partial T_{\eta}}{\partial t}}_{\text {accumulation }}+\underbrace{\left(\rho C_{\mathrm{P}}\right)_{\eta} \mathbf{V}_{\eta} \cdot \nabla T_{\eta}}_{\text {convection }}$

$$
=\underbrace{\nabla \cdot\left(\lambda_{\eta}^{*} \nabla T_{\eta}\right)}_{\text {conduction }}+Q_{\eta},
$$

$P_{\eta}=\frac{\rho_{\beta \eta} R T_{\eta}}{M_{\beta \eta}}$.

Boundary conditions:

$$
\begin{aligned}
& -\left.\mathbf{D}_{j \eta}^{*} \cdot \frac{\partial C_{j \eta}}{\partial r}\right|_{r=R_{\mathrm{p}}}=\alpha\left(C_{j \eta}-C_{\infty}\right), \\
& -\left.\lambda_{\eta}^{*} \frac{\partial T_{\eta}}{\partial r}\right|_{r=R_{\mathrm{p}}}=h\left(T_{\eta}-T_{\infty}\right)+Q_{\mathrm{rad}}
\end{aligned}
$$

The correlations for the calculation of Sherwood and Nusselt number in the case of a single sphere, used in the calculation of the mass and heat transfer coefficient values $\alpha$ and $h$, are as follows:

$$
\mathrm{Nu}=2+\left(0.4 \mathrm{Re}^{0.5}+0.06 \operatorname{Re}^{2 / 3}\right) \operatorname{Pr}^{0.4},
$$

$\mathrm{Sh}=2+\left(0.4 \mathrm{Re}^{0.5}+0.06 \mathrm{Re}^{2 / 3}\right) \mathrm{Sc}^{0.4}$

The effective diffusion coefficient is calculated as

$\mathbf{D}_{j \eta}^{*}=\frac{\varepsilon_{\eta} D_{j}}{\tau}$. 
Table 4

Numerical data

\begin{tabular}{ll}
\hline$\rho_{\sigma \eta}\left(\mathrm{kg} \mathrm{m}^{-3}\right)$ & 1900 \\
$\mu(\mathrm{Pas})$ & $4.35 \times 10^{-5}$ \\
$\tau$ & 1.5 \\
$\mathbf{K}_{\eta}\left(\mathrm{m}^{2}\right)$ & $10^{-11}$ \\
$\varepsilon_{\eta}$ & 0.75 \\
$P_{\eta}(\mathrm{Pa})$ & $10^{5}$ \\
\hline
\end{tabular}

\section{Appendix B. Numerical data for the simulations}

First, we recall here the expression for the reaction rate used in the model,

$R_{\text {char }}=-\frac{k_{1} p_{\mathrm{H}_{2} \mathrm{O}}+k_{4} p_{\mathrm{H}_{2} \mathrm{O}} p_{\mathrm{H}_{2}}+k_{5} p_{\mathrm{H}_{2} \mathrm{O}}^{2}}{1+k_{2} p_{\mathrm{H}_{2}}+k_{3} p_{\mathrm{H}_{2} \mathrm{O}}} \rho_{\eta} S_{\mathrm{r}}$,

where the parameters $k_{i}$ are described by an Arrhenius law,

$k_{i}=A_{i} \exp \left(-\frac{E_{i}}{R T}\right)$.

The obtained values of kinetic parameters are given below:

$$
\begin{aligned}
& A_{1}=2.09 \times 10^{-4} \mathrm{~m}^{-2} \mathrm{~s}^{-1} \mathrm{~atm}^{-1}, \\
& E_{1}=158.6 \mathrm{~kJ} \mathrm{~mol}^{-1}, \\
& A_{3}=9.69 \times 10^{2} \mathrm{~atm}^{-1}, \\
& E_{3}=50.32 \mathrm{~kJ} \mathrm{~mol}^{-1}, \\
& A_{4}=7.84 \times 10^{-7} \mathrm{~m}^{-2} \mathrm{~s}^{-1} \mathrm{~atm}^{-2}, \\
& E_{4}=95.1 \mathrm{~kJ} \mathrm{~mol}^{-1}, \\
& k_{2}=1.16 \times 10^{-5} \mathrm{~atm}^{-1}, \\
& k_{5}=6.38 \times 10^{-16} \mathrm{~m}^{-2} \mathrm{~s}^{-1} \mathrm{~atm}^{-2} .
\end{aligned}
$$

The initial surface area $S_{\mathrm{r}}^{0}$ was estimated from BET analysis and fixed at $275 \mathrm{~m}^{2} \mathrm{~cm}^{-3}$.

The enthalpy change due to the steam gasification reaction, used in the calculation of the thermal source term $Q_{\eta}$, was found to be $135.8 \mathrm{~J} \mathrm{~mol}^{-1}$.

The other values of the physical and chemical constants common to all the simulations are presented in Table 4.

\section{References}

[1] M. Barrio, B. Gobel, H. Risnes, U. Henriksen, J.E. Hustad, L.H. Sorensen, in: A. Bridgwater (Ed.), Progress in Thermochemical Biomass Conversion, Blackwell, Oxford, 2001, pp. 32-46.

[2] M. Hemati, C. Laguerie, Entropie 142 (1988) 29-40.

[3] J.R. Richard, M. Cathonnet, J.P. Rouan, in: R. Overend, T. Milne, L. Mudge (Eds.), Fundamentals of Thermochemical Biomass Conversion, Elsevier, New York, 1982, pp. 589-599.
[4] M. Zhi-Hua, Z. Cheng-Fang, Z. Zi-Bin, S. Er-Li, Fuel Process. Technol. 31 (1992) 69-76.

[5] N. Standish, A.F.A. Tanjung, Fuel 67 (1988) 666-672.

[6] M. Kumar, R.C. Gupta, Fuel 73 (12) (1994) 1922 1925.

[7] S. Dasappa, P.J. Paul, H.S. Mukunda, U. Shrinivasa, Chem. Eng. Sci. 49 (2) (1994) 223-232.

[8] G. Kovacik, A. Chambers, B. Ozum, Can. J. Chem. Eng. 69 (1991) 811-815.

[9] D.P. Ye, J.B. Agnew, D.K. Zhang, Fuel 77 (11) (1998) 1209-1219.

[10] G. Chen, K. Sjostrom, E. Bjornbom, Ind. Eng. Chem. Res. 31 (1992) 2764-2768.

[11] D.G. Roberts, D.J. Harris, T.F. Wall, Energy Fuels 17 (2003) 887-895.

[12] E. Cetin, B. Moghtaderi, R. Gupta, T.F. Wall, Fuel 83 (16) (2004) 2139-2150.

[13] C. Fushimi, K. Araki, Y. Yamaguchi, A. Tsutsumi, Ind. Eng. Chem. Res. 42 (17) (2003) 3922-3928.

[14] P.L.J. Walker, in: R. Overend, T. Milne, L. Mudge (Eds.), Fundamentals of Thermochemical Biomass Conversion, Elsevier, New York, 1985, pp. 485-509.

[15] F. Mermoud, S. Salvador, L. Van de Steene, F. Golfier, Fuel, in press.

[16] C.A. Gurgel Veras, J. Saastamoinen, J.A. Carvalho Jr., M. Aho, Combust. Flame 116 (4) (1999) 567-579.

[17] B. Gobel, U. Henriksen, B. Qvale, N. Houbak, in: A. Bridgwater (Ed.), Progress in Thermochemical Biomass Conversion, Blackwell, Oxford, 2001, pp. 92 108.

[18] R. He, T. Suda, T. Fujimori, J.i. Sato, Int. J. Heat Mass Transfer 46 (19) (2003) 3619-3627.

[19] H.C. Kung, Combust. Flame 18 (1972) 185-195.

[20] J.C. Lee, R.A. Yetter, F.L. Dryer, Combust. Flame 101 (4) (1995) 387-398.

[21] S. Dasappa, P.J. Paul, H.S. Mukunda, U. Shrinivasa, Proc. Combust. Inst. 27 (1998) 1335-1342.

[22] B. Peters, C. Bruch, Chemosphere 42 (5-7) (2001) 481-490.

[23] C.E. Byrne, D.C. Nagle, Carbon 35 (2) (1997) 259266.

[24] S. Dutta, C.Y. Wen, R.J. Belt, Ind. Eng. Chem. 16 (1977) 20-30.

[25] I. Aarna, E.M. Suuberg, Proc. Combust. Inst. 27 (1998) 2933-2939.

[26] P.R. Walker, R.J.J. Foresti, C.C. Wright, Ind. Eng. Chem. 45 (8) (1953) 1703-1710.

[27] S. Manocha, V. Chauhan, L. Manocha, Carbon Sci. 3 (3) (2002) 133-141.

[28] R.P.W.J. Struis, C. Von Scala, S. Stucki, R. Prins, Chem. Eng. Sci. 57 (2002) 3581-3592.

[29] H.A. Jakobsen, H. Lindborg, V. Handeland, Comput. Chem. Eng. 26 (3) (2002) 333-357.

[30] J.F. Kanney, C.T. Miller, C.T. Kelley, Adv. Water Resour. 26 (3) (2003) 247-261.

[31] A.R. Bahadir, F.B. Ellerby, Appl. Math. Comput. 125 (2-3) (2002) 347-358.

[32] M. Gupta, J. Yang, C. Roy, Fuel 82 (8) (2003) 919-927.

[33] I.I. Kantorovich, E. Bar-Ziv, Fuel 78 (3) (1999) 279 299.

[34] F. Marquez-Montesinos, T. Cordero, J. RodriguezMirasol, J.J. Rodriguez, Fuel 81 (2002) 423-429. 
[35] H.J. Muhlen, K.H. Van Heek, H. Juntgen, Fuel 64 (1985) 944-949.

[36] F.F. Peng, I.C. Lee, R.Y.K. Yang, Fuel Process. Technol. 41 (3) (1995) 233-251.

[37] J. Gadsby, C.N. Hinshelwood, K.W. Sykes, Proc. R. Soc. London Ser. A 187 (1946) 129.

[38] J.D. Blackwood, F. McGrory, Aust. J. Chem. 11 (1958) 16-23.

[39] L.R. Radovic, P.L.J. Walker, R.G. Jenkins, Fuel 62 (1983) 849-856.

[40] W. Klose, M. Wolki, Fuel 84 (7-8) (2005) 885-892.

[41] J.M. Encinar, J.F. Gonzalez, J.J. Rodriguez, M.J. Ramiro, Fuel 80 (14) (2001) 2025-2036.

[42] T. Alvarez, A.B. Fuertes, J.J. Pis, P. Ehrburger, Fuel 74 (5) (1995) 729-735.
[43] A. Molina, F. Mondragon, Fuel 77 (15) (1998) 18311839.

[44] T. Liliedahl, K. Sjostrom, Fuel 76 (1) (1997) 29-37.

[45] S.K. Bhatia, B.J. Vartak, Carbon 34 (11) (1996) 13831391.

[46] M.G. Lussier, Z. Zhang, D.J. Miller, Carbon 36 (9) (1998) 1361-1369.

[47] S. Ergun, J. Phys. Chem. 60 (1956) 480-485.

[48] F.Y. Wang, S.K. Bhatia, Chem. Eng. Sci. 56 (12) (2001) 3683-3697.

[49] S. Whitaker, AIChE J. 13 (1967) 420-467.

[50] F.A. Howes, S. Whitaker, Chem. Eng. Sci. 40 (8) (1985) 1387-1392.

[51] A. Ahmadi, M. Quintard, S. Whitaker, Adv. Water Resour. 22 (1) (1998) 59-86. 